University of Montana

ScholarWorks at University of Montana

\title{
Combining demographic and genetic factors to assess population vulnerability in stream species
}

\author{
Erin Landguth \\ The University of Montana \\ C. C. Muhlfeld \\ University of Montana - Missoula \\ R. S. Waples \\ National Marine Fisheries Service \\ L. Jones \\ University of Montana - Missoula \\ Winsor H. Lowe \\ University of Montana - Missoula, winsor.lowe@umontana.edu \\ See next page for additional authors
}

Follow this and additional works at: https://scholarworks.umt.edu/biosci_pubs

Part of the Biology Commons, and the Population Biology Commons

Let us know how access to this document benefits you.

\section{Recommended Citation}

E. L. Landguth, C. C. Muhlfeld, R. S. Waples, L. Jones, W. H. Lowe, D. Whited, J. Lucotch, H. Neville, and G. Luikart 2014. Combining demographic and genetic factors to assess population vulnerability in stream species. Ecological Applications 24:1505-1524. http://dx.doi.org/10.1890/13-0499.1

This Article is brought to you for free and open access by the Biological Sciences at ScholarWorks at University of Montana. It has been accepted for inclusion in Biological Sciences Faculty Publications by an authorized administrator of ScholarWorks at University of Montana. For more information, please contact scholarworks@mso.umt.edu. 


\section{Authors}

Erin Landguth, C. C. Muhlfeld, R. S. Waples, L. Jones, Winsor H. Lowe, Diane C. Whited, J. Lucotch, H. Neville, and Gordon Luikart 


\title{
Combining demographic and genetic factors to assess population vulnerability in stream species
}

\author{
E. L. Landguth,${ }^{1,7}$ C. C. Muhlfeld,${ }^{2,3}$ R. S. Waples,${ }^{4}$ L. Jones, ${ }^{1,2}$ W. H. Lowe,,${ }^{1}$ D. Whited,${ }^{3}$ J. Lucotch,${ }^{1}$ \\ H. Neville, ${ }^{5}$ and G. Luikart ${ }^{6}$ \\ ${ }^{1}$ University of Montana, Division of Biological Sciences, 32 Campus Drive, Missoula, Montana 59812 USA \\ ${ }^{2}$ U.S. Geological Survey, Northern Rocky Mountain Science Center, Glacier National Park, West Glacier, Montana 59936 USA \\ ${ }^{3}$ Flathead Lake Biological Station, University of Montana, Polson, Montana 59860 USA \\ ${ }^{4}$ Northwest Fisheries Science Center, National Marine Fisheries Service, 2725 Montlake Boulevard East, \\ Seattle, Washington 98112 USA \\ ${ }^{5}$ Trout Unlimited, 910 West Main Street, Suite 342, Boise, Idaho 83702 USA \\ ${ }^{6}$ Flathead Lake Biological Station, Fish and Wildlife Genomics Group, Division of Biological Sciences, University of Montana, \\ Polson, Montana 59860 USA
}

\begin{abstract}
Accelerating climate change and other cumulative stressors create an urgent need to understand the influence of environmental variation and landscape features on the connectivity and vulnerability of freshwater species. Here, we introduce a novel modeling framework for aquatic systems that integrates spatially explicit, individual-based, demographic and genetic (demogenetic) assessments with environmental variables. To show its potential utility, we simulated a hypothetical network of 19 migratory riverine populations (e.g., salmonids) using a riverscape connectivity and demogenetic model (CDFISH). We assessed how stream resistance to movement (a function of water temperature, fluvial distance, and physical barriers) might influence demogenetic connectivity, and hence, population vulnerability. We present demographic metrics (abundance, immigration, and change in abundance) and genetic metrics (diversity, differentiation, and change in differentiation), and combine them into a single vulnerability index for identifying populations at risk of extirpation. We considered four realistic scenarios that illustrate the relative sensitivity of these metrics for early detection of reduced connectivity: (1) maximum resistance due to high water temperatures throughout the network, (2) minimum resistance due to low water temperatures throughout the network, (3) increased resistance at a tributary junction caused by a partial barrier, and (4) complete isolation of a tributary, leaving resident individuals only. We then applied this demogenetic framework using empirical data for a bull trout (Salvelinus confluentus) metapopulation in the upper Flathead River system, Canada and USA, to assess how current and predicted future stream warming may influence population vulnerability. Results suggest that warmer water temperatures and associated barriers to movement (e.g., low flows, dewatering) are predicted to fragment suitable habitat for migratory salmonids, resulting in the loss of genetic diversity and reduced numbers in certain vulnerable populations. This demogenetic simulation framework, which is illustrated in a web-based interactive mapping prototype, should be useful for evaluating population vulnerability in a wide variety of dendritic and fragmented riverscapes, helping to guide conservation and management efforts for freshwater species.
\end{abstract}

Key words: connectivity; dispersal; gene flow; genetic differentiation; genetic diversity; landscape genetics; population viability; risk maps; Salvelinus confluentus; stream barrier; stream networks; vulnerability assessments.

\section{INTRODUCTION}

Because salmonid populations tend to show watershed scale variation in both demographic and genetic traits, we propose that models combining demographic, genetic and spatial data are promising tools for improving their management and conservation.

-Frank et al. (2011)

Manuscript received 14 March 2013; revised 10 December; accepted 18 December 2013; final version received 14 January 2014. Corresponding Editor: S. Oyler-McCance.

${ }^{7}$ E-mail: erin.landguth@mso.umt.edu
Climate change is increasingly threatening the biodiversity of aquatic ecosystems worldwide (Walther et al. 2002, Parmesan and Yohe 2003, Isaak et al. 2012). Combined with additional stressors, such as habitat loss and invasive species, these changes are likely to shift patterns of distribution, abundance, phenology, and genetic diversity in many species (Root et al. 2003, Parmesan 2006). This is particularly true for many aquatic species restricted to stream environments with spatial gradients in temperature, flow, and physical habitat conditions (Vannote et al. 1980, Grant et al. 2007). Understanding how changes in these environ- 
mental conditions influence patterns of demographic and genetic variation in stream networks is essential to designing effective conservation measures at both local and global scales.

Vulnerability assessments are a principal tool to understand the potential impacts of environmental change on populations, species, and ecosystems, and to inform conservation planning and management decisions (Cross et al. 2012). Such assessments allow us to explore the complex interactions caused by environmental change and their potential effects on local populations, improving our ability to identify vulnerable populations, species, and river reaches, and providing insight on the source of this vulnerability. Previously, the vulnerability of threatened and exploited stream species has been assessed based on either genetic or demographic factors alone (e.g., Fagan 2002, Jaríc et al. 2010). However, the importance of considering both demographic and genetic factors in understanding species responses to stream (riverscape; Fausch et al. 2002) variation has been highlighted in recent reviews (e.g., Grant et al. 2007, Frank et al. 2011). Similarly, the importance of simulation modeling for assessing genetic vulnerability has been emphasized in a number of recent studies (e.g., Balkenhol et al. 2009, Epperson et al. 2010). As a result, the need to integrate demographic and genetic effects in simulation models (defined herein as demogenetic modeling; Frank et al. 2011) has become more apparent. This need has been further reinforced by our growing understanding of the complex interactions between demographic and genetic effects on population persistence (Mills 2007, Lowe and Allendorf 2010, Luque et al. 2012). It is especially clear that individualbased simulation tools will be valuable for assessing genetic (gene flow, genetic drift, and natural selection) and demographic (reproduction, survival, dispersal, and population size) consequences of the complex, climaterelated changes to aquatic and terrestrial systems in coming decades (Balkenhol and Landguth 2011).

We recently introduced cost distance fisheries (CDFISH), a simulator of population genetics, demography, and connectivity (dispersal and gene flow) for a wide range of environmental assessments of aquatic organisms in complex stream networks (Landguth et al. 2012a). The simulation program is designed to enable spatially explicit quantification of how the stream environment affects functional (genetic and demographic) connectivity patterns in riverscapes. To our knowledge, this program represents the only available individual-based, spatially explicit program to integrate demographic, genetic, and environmental data for aquatic systems.

CDFISH simulates the movement of individuals among populations through time, employing userdefined functions of individual migration, reproduction, mortality, residency, and dispersal on a continuous riverscape. At the stream-reach scale (local scale), the program can be used to assess potential impacts of environmental and/or human-induced perturbations, which can cause rapid changes in the demographic and genetic structure of populations due to reduced connectivity and degradation of suitable habitats (Pertoldi and Topping 2004). At larger scales, the program can be used to assess how the structure and complexity of the channel network affects the demographics and genetics of populations by influencing dispersal among populations, and by interacting with microevolutionary processes (gene flow and genetic drift).

Salmonids are especially vulnerable to climate-induced warming or other human-mediated impacts in freshwater ecosystems because (1) they have relatively narrow thermal tolerances and require streams and lakes with cold, high-quality habitats, (2) they require access to various types of complementary habitats throughout their life cycle (Dunning et al. 1992, Schlosser and Angermeier 1995, Northcote 1997), and (3) their distributions and abundances in dendritic stream systems are strongly influenced by temperature, stream flow gradients, and physical barriers (e.g., waterfalls; Fagan 2002, Fausch et al. 2002). Moreover, many native salmonid populations are already small, fragmented, and isolated with only limited genetic exchange, thereby increasing their vulnerability to stochastic disturbances (e.g., wildfire and debris flows; Allendorf and Luikart 2007, Mills 2007).

Here, we present a novel riverscape resistancemodeling framework that combines the use of CDFISH with spatiotemporal changes in abiotic variables (e.g., dams, stream temperature, or flow regime) to assess and map the vulnerability of aquatic populations in a stream network. We focus the application on a large, complex, and connected river and lake network containing migratory salmonid (e.g., trout and char) populations that migrate throughout a freshwater river and lake network in northwestern Montana, USA, and southeastern British Columbia, Canada. Our first objective was to use the CDFISH-based framework to explore the behavior of genetic and demographic population vulnerability metrics in response to temperature and physical barrier-induced resistances to movement. This allowed us to assess effects of thermal suitability and connectivity of stream habitats on population vulnerability. Our second objective was to develop and evaluate summary indices that combine demographic and genetic vulnerability metrics to assess the spatiotemporal change in overall vulnerability of populations. We considered four connectivity scenarios that illustrate the relative sensitivity of the six metrics and the combined vulnerability indices for detecting reduced connectivity (and population vulnerability), and for inferring the causes of vulnerability (e.g., partial vs. complete isolation). Finally, we applied this demogenetic framework to a bull trout metapopulation in the upper Flathead River system, Canada and USA, to help assess how current and predicted future stream warming may influence population viability. Our approach provides a general 
framework useful for population vulnerability assessments and strategic targeting of mitigation or restoration efforts in spatially complex aquatic systems experiencing multiple stressors.

\section{Methods}

\section{Riverscape demogenetics simulation program}

We used a spatially explicit, individual-based, riverscape demogenetic program (CDFISH v0.52; Landguth et al. 2012a) to assess how stream resistance and other features influence indices of population vulnerability in a hypothetical network of migratory trout populations. Spatial structure was based on the configuration of 19 trout populations in the upper Flathead River basin in northwestern Montana and southeastern British Columbia (Fig. 1). We modeled a life-history scenario common to many inland salmonids, in which populations can sustain both resident (remaining in natal streams throughout life) and migratory life-history strategies. Migratory individuals reared in natal streams, migrated downstream to a large lake (Flathead Lake) where they grew to maturity, then migrated upstream to spawn in natal streams (Fig. 1). We also allowed some degree of "straying" between populations, where individuals reared in a natal stream and spawned in a different stream. In CDFISH, individual movement in the stream network is a function of stream resistance, and we considered four scenarios: (1) maximum resistance as a function of environment (stream temperature gradient over an extended river distance), (2) minimum resistance as a function of environment, (3) partial isolation, i.e., increased resistance caused by a partial barrier such as a debris flow or dam, and (4) complete, long-term isolation of a stream, leaving resident individuals only (Fig. 1).

CDFISH simulates demographic and genetic connectivity for $(x, y)$-located individuals as functions of individual-based behavior and movement (mating and dispersal) and vital rates (birth and death) in a stream resistance surface. A resistance surface consists of a spatial map of gridded cells, where each cell value (pixel) represents the unit cost of crossing each location. Pixels are given weights, or resistance values, reflecting the presumed influence of each variable (e.g., temperature, slope) on movement or connectivity of the species in question (e.g., Dunning et al. 1992, Cushman et al. 2006, Spear et al. 2010). In our hypothetical simulations, we used a spatially explicit model of stream temperature (1$18^{\circ} \mathrm{C}$, 22-m resolution) recently developed for the Flathead system (Jones et al. 2014) to represent resistance surface values, and assumed a linear response of resistance to temperature.

From a given riverscape resistance surface, CDFISH requires a matrix of cost to movement as input. We computed a shortest-cost path algorithm between all pairs of populations on the riverscape with UNICOR (Landguth et al. 2012b). The program incorporates movement to and from a source location, which was relevant here because of the presence of Flathead Lake, which represents the furthest downstream habitat used by migratory fish in the system (Fig. 1). The cost values reflect penalties as a function of riverine distance and the accumulated temperature values along the entire river network.

Scenarios 1 and 2 (maximum and minimum resistance, respectively) assess demogenetic responses in populations with the maximum and minimum cost values that occur on this riverscape network (see Fig. 1; populations 19 and 9, respectively). To illustrate additional abiotic or biotic resistance features that could impede movement within a stream network (e.g., barriers), scenario 3 imposes a partial barrier below population 11 by increasing the resistance values for pixels at this tributary's confluence with the mainstem river (Fig. 1). This partial barrier resulted in costs to movement for an individual destined for population 11 approximately equal to the cost to movement for an individual traversing the entire riverscape (i.e., maximum cost to movement from the lake to population 19). For complete isolation, scenario 4, we chose population 12. We did not increase barrier resistance, but rather ecologically isolated the population by assuming a 1.0 probability of residency. This ecological isolation is realistic for many populations that suddenly become isolated by very low flows (dewatering) and/or very high temperatures. Cost distance values from all populations to the lake source are shown in Table 1.

In CDFISH, individual locations, age structure, and sex are user-defined within populations; here we initialized each population with 50 individuals, and specified non-overlapping generations and an equal sex ratio. The genotypes in CDFISH can be initialized randomly or with empirical data. In this illustrative example, we chose the following burn-in procedure before using our given resistance surface: the genotypes for each individual were initiated with 20 independent loci and 20 random alleles per locus (maximum allelic diversity and even allele frequencies) with no mutation, which is reasonable, considering the short simulation time period. We first used an island model of migration (i.e., equal probability of migration and straying for each subpopulation) for 10 generations to establish a genetic burn-in pattern before our simulations started with the given riverscape resistance surface. After this burn-in period, our initial 19 populations had a total of 400 alleles (each population mean had expected and observed heterozygosity of approximately 0.83 and 0.85 , respectively, and 211 alleles on average). The riverscape resistance surface was then used for an additional 75 generations to determine increasing or decreasing population size and genetic variation resulting from a combination of individual migratory behaviors and the dynamics of population vital rates.

Offspring can either reside in the local population or migrate to the lake source (Flathead Lake). For each population (except 12), the probability of residency was 
set to 0.1 . Offspring that migrated to the lake source (probability 0.9 ) later either migrated back to their original population (natal stream population), strayed (i.e., dispersed) to a different population (a 0.01 probability in these simulations), or died. For those individuals that strayed, we chose the target (recipient) population using probabilities of movement from the natal population to an adjacent population based on the least-cost path directly to each adjacent population from the natal population. For example, a strayer (disperser) is most likely to disperse to the adjacent population with the least cost (resistance to movement) from its natal stream. If two adjacent streams have the same resistance to movement, they would have the same probability (from a random draw) of receiving the disperser.

In CDFISH, the success or failure (death) of migration and straying events are modeled as probabilistic functions of the cumulative cost of moving across the riverscape resistance surface; from the lake source back to a natal stream for most migratory individuals, or from population to population for straying individuals (cost calculated from resistance values with UNICOR; Landguth et al. 2012b). The movement cost function was scaled between the minimum cost distance and the maximum cost distance on the riverscape. For example, if the cost distance was the minimum value, then the probability of successful movement was 1.0 ; if the cost distance was at the maximum migration distance, then the probability of movement was 0.0. Individuals that were successful at migration (due to a random draw that was less than or equal to the probability of movement) filled spawning sites within a local stream population randomly. If the individual failed at migration, due to a random draw that was greater than the probability of movement, it was considered a mortality. All probability values of successfully migrating back to original populations (natal streams) are shown in Table 1.

CDFISH allows for various mating structures. Based on the biology of most salmonid species, we chose a polygamous random mating structure within populations, where each male could mate randomly with more than one female. Each mated female produced a random number of offspring, drawn from a Poisson distribution with a mean of four. Populations near the carrying capacity $(n=50)$ thus produced an excess of individuals each generation. This allowed for the riverscape resistance surface to influence population vulnerability metrics within and among populations. In each of the 19 populations, excess offspring were discarded once all 50 locations were randomly occupied by a resident, migratory, or straying individual (i.e., forcing individuals out of the simulation study once all available home ranges are occupied; Balloux 2001, Landguth and Cushman 2010). We performed 100 independent Monte Carlo replicates to quantify the variability in population dynamics and spatial genetic structure.

\section{Genetic vulnerability mapping}

Our goal was to produce a genetic vulnerability index for each population to identify populations at risk under various riverscape scenarios (e.g., temperature or projected change in flows). Genetic vulnerability was defined as a combination of three metrics that estimate genetic diversity within populations, differentiation between populations, and temporal change in differentiation between populations (Fig. 2). For each population $j$ at every generation $t$ we calculated the following metrics: (1) allelic diversity within a population, (2) mean of the pairwise genetic differentiation between a (focal) population and every other population, and (3) temporal change in population-specific pairwise genetic differentiation. The motivation for the three metrics is as follows.

Maintaining diversity within a population is important for avoiding inbreeding depression (Allendorf and Ryman 2002) and allowing adaptation to future environmental change. We chose allelic diversity (rather than heterozygosity) because it is more sensitive for early detection of population fragmentation or decline (Leberg 1992, Spencer et al. 2000). We estimated allelic diversity within a population by quantifying the proportion of initially present alleles that remained after each generation in the simulation (Allendorf 1986)

$$
a_{i j t}=\frac{A_{i j t}-1}{A_{i j 0}-1}
$$

where $A_{i j t}$ is the number of alleles at locus $i$ in population $j$ at generation $t$, and $A_{i j 0}$ is the number of alleles at locus $i$ in population $j$ at the initial generation. When mutation rate is 0 , overall number of alleles will tend to decline over time, but $a_{i j t}$ can increase locally due to immigration. In the case of monomorphic loci, $a_{i j t}$ was set to 0 . An overall measure of allelic diversity can be obtained by summing $a_{i j t}$ across loci $L$

$$
a_{j \cdot t}=\frac{\sum_{i=1}^{L} a_{i j t}}{L} .
$$

This overall index equals zero if the population has no genetic variation at any locus (i.e., one allele at all loci). Here, $a_{j \cdot t}$ refers to the measure summed across all loci.

For each pair of populations $j$ and $k$, at specified generations $t$, we calculated an overall pairwise genetic differentiation $\left(G_{\mathrm{ST}, j k t}\right)$ across all loci using the method of Nei (1973). At each generation $t$, we calculated a mean pairwise $G_{\mathrm{ST}}$ for each population $j$ as

$$
G_{\mathrm{ST}, j t}=\sum_{k=1, k \neq j, N \neq 0}^{n} \frac{G_{\mathrm{ST}, j k t}}{n-1}
$$

where $n$ is the number of populations, $N$ is the number of individuals within population $k$, and $G_{\mathrm{ST}, j k t}=1-$ 


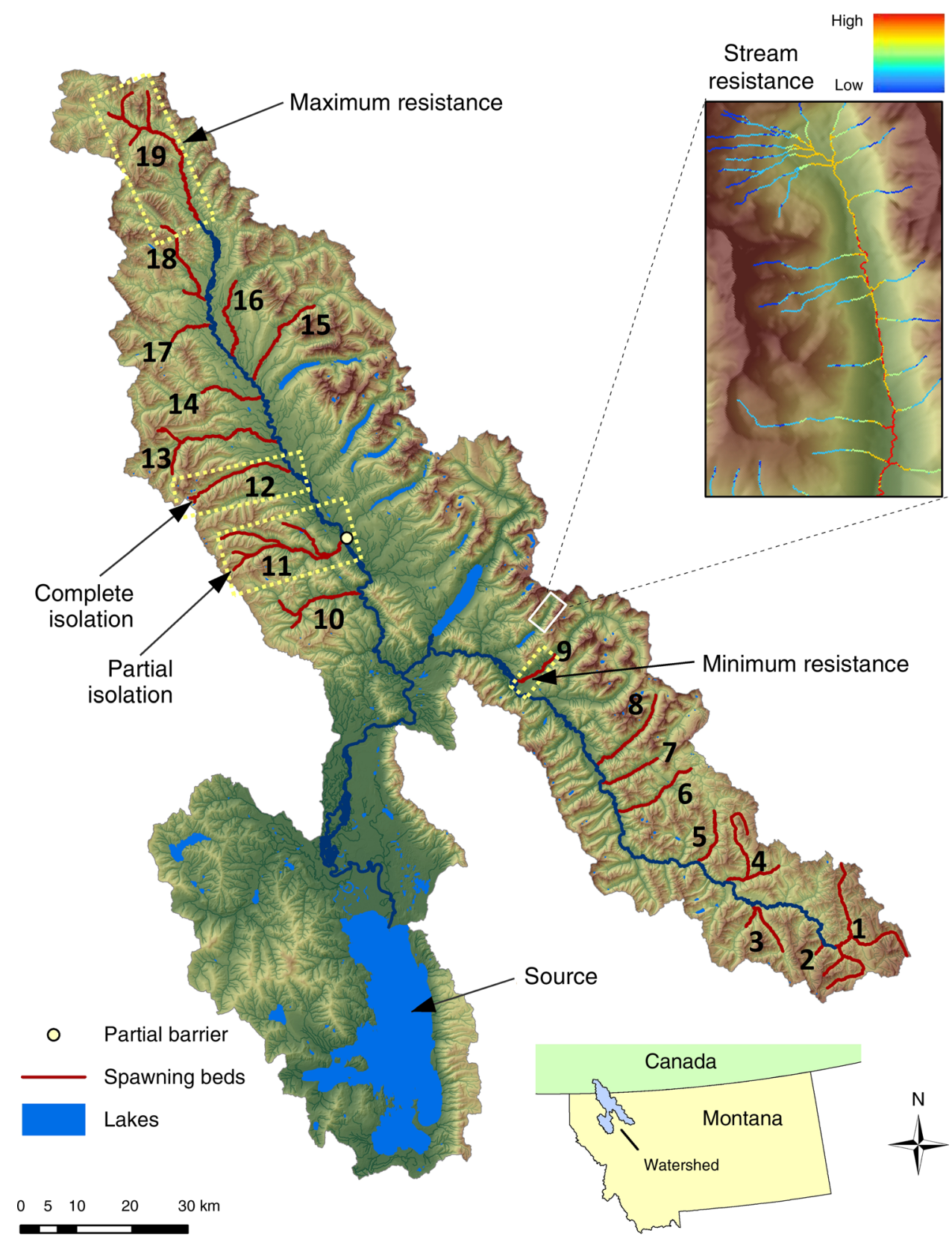

FIG. 1. Simulated riverscape in a hypothetical network of migratory trout populations, with 19 populations and 50 individuals per population at the beginning of the simulation. The upper right inset illustrates the resistance surface for a portion of the network for which varying degrees of resistance values are assigned to each pixel. The lower right inset shows the location of the Flathead River basin within which the riverscape is simulated. The locations of studies for four scenarios are shown in dotted yellow boxes: maximum resistance (scenario 1), minimum resistance (scenario 2), partial isolation (scenario 3), and complete isolation (scenario 4). The lake source is Flathead Lake (Montana, USA), to which some species that have a migratory life history (e.g., bull trout) migrate.

$H_{\mathrm{S}, j k t} / H_{\mathrm{T}, j k t} . H_{\mathrm{S}, j k t}$ is the intrapopulation gene diversity and $H_{\mathrm{T}, j k t}$ is the total gene diversity as defined by Nei (1973). We used the nearly unbiased estimators for both $H_{\mathrm{S}, j k t}$ and $H_{\mathrm{T}, j k t}$ derived by Nei and Chesser (1983) to correct for sample size. Substituting these into Eq. 3 produces the metric $\hat{G}_{\mathrm{ST} j \cdot t}$, which sums across all loci.
The third metric we used in the genetic vulnerability index was the temporal change in genetic differentiation, which can affect populations in two ways. Preventing the rapid increase in genetic differentiation (toward isolation) is important to avoid fixation of deleterious alleles, inbreeding, and loss of adaptive alleles in a 
TABle 1. Cost distances (cumulative total resistance: riverine distance, temperature, and/or barrier) faced by an adult trout when migrating from its lake source to its natal stream and functional probability of migrating from the lake source to each of 19 populations.

\begin{tabular}{ccc}
\hline \hline Population & Cost & Probability \\
\hline 1 & $6.443 \times 10^{7}$ & 0.05 \\
2 & $6.434 \times 10^{7}$ & 0.12 \\
3 & $6.418 \times 10^{7}$ & 0.24 \\
4 & $6.412 \times 10^{7}$ & 0.28 \\
5 & $6.402 \times 10^{7}$ & 0.36 \\
6 & $6.376 \times 10^{7}$ & 0.57 \\
7 & $6.362 \times 10^{7}$ & 0.67 \\
8 & $6.362 \times 10^{7}$ & 0.68 \\
$\mathbf{9}$ & $\mathbf{6 . 3 1 9} \times \mathbf{1 0}$ & $\mathbf{1 . 0 0}$ \\
10 & $6.320 \times 10^{7}$ & 0.99 \\
11 & $6.446 \times 10^{7}$ & 0.02 \\
12 & $6.362 \times 10^{7}$ & 0.67 \\
13 & $6.373 \times 10^{7}$ & 0.58 \\
14 & $6.383 \times 10^{7}$ & 0.51 \\
15 & $6.393 \times 10^{7}$ & 0.43 \\
16 & $6.398 \times 10^{7}$ & 0.39 \\
17 & $6.403 \times 10^{7}$ & 0.35 \\
18 & $6.418 \times 10^{7}$ & 0.24 \\
$\mathbf{1 9}$ & $\mathbf{6 . 4 4 9} \times \mathbf{1 0}$ & $\mathbf{0 . 0 0}$ \\
Mean & $6.394 \times 10^{7}$ & 0.43 \\
SD & 381615.8 & 0.295 \\
\end{tabular}

Notes: The functional probabilities are based on a linear function scaled to the minimum and maximum cost distance values in the stream network (populations 9 and 19, respectively, in boldface). The mean and standard deviation among all populations are also reported. Population 19 represents scenario 1 (maximum resistance), population 9 represents scenario 2 (minimum resistance), population 11 represents scenario 3 (partial isolation), and population 12 represents scenario 4 (complete isolation).

population (e.g., Luikart et al. 1998). However, large decreases in genetic differentiation can indicate homogenization and loss of local adaptations (e.g., Ryman et al. 1995). We therefore defined temporal change in genetic differentiation as

$$
\Delta \hat{G}_{\mathrm{ST} j \cdot t}=\left|\hat{G}_{\mathrm{ST} j \cdot t}-\hat{G}_{\mathrm{ST} j \cdot t 0}\right| .
$$

$\Delta \hat{G}_{\mathrm{ST} j \cdot t}$ is the absolute value of the difference in $\hat{G}_{\mathrm{ST} j \cdot t}$ from the initial level of genetic differentiation $\hat{G}_{\mathrm{ST} j \cdot t 0}$.

Based on the assumption that each metric holds roughly equal weight on the overall genetic vulnerability index $\left(G_{\mathrm{v}}\right)$, we normalized each metric to range between 0 and 1 as follows. First, the domain of allelic diversity is $[0.0,1.0]$; therefore, no normalization procedure is needed. Allelic diversity is considered a positive influence on population persistence, thus high allelic diversity corresponds to low genetic vulnerability. Second, for highly polymorphic markers like microsatellites, $\hat{G}_{\mathrm{ST} j \cdot t}$ will never approach 1 , so we used the standardized measure of genetic differentiation, $\hat{G}_{\mathrm{ST} j \cdot t}^{\prime}=\hat{G}_{\mathrm{ST} j \cdot t} /$ $\hat{G}_{\mathrm{ST} j \mathrm{tmax}}($ Hedrick 2005), in which the fixation index is rescaled between 0.0 and 1.0. A sudden or rapid increase to high genetic differentiation (e.g., $G_{\mathrm{ST}} \gg 0.2$ ) is considered potentially harmful for a population due to phenomena such as local inbreeding and increase in frequency of deleterious alleles (Lande 1994, Allendorf et al. 2008); therefore, high differentiation increases the vulnerability metric. Finally, as for genetic differentiation, we used Hedrick's (2005) standardized measure for normalizing the temporal change in genetic differentiation, resulting in the metric $\Delta \hat{G}^{\prime} \mathrm{ST} j \cdot t$. Here, any substantial change in genetic differentiation (i.e., isolation or homogenization) from the initial generation is considered potentially harmful for a population and thus increases the population's vulnerability.

The genetic vulnerability index for any population $j$ at a given $t$ can be expressed as

$$
G_{\mathrm{v}, j t}=\left(1-a_{j \cdot t}\right)+\hat{G}_{\mathrm{ST} j \cdot t}^{\prime}+\Delta \hat{G}^{\prime} \mathrm{ST} j \cdot t \cdot
$$

The three normalized metric values are added, after conversion in the case of allelic diversity $\left(1-a_{j \cdot t}\right)$, allowing $G_{\mathrm{v}, j t}$ to be on the closed interval between 0 and 3 , where $G_{\mathrm{v}, j t}=0$ reflects low genetic vulnerability and $G_{\mathrm{v}, j t}=3$ reflects high genetic vulnerability. All metrics were calculated in scripts written in Python (v2.7.6.; Python Software Foundation), but confirmed independently using the diveRsity package(Keenan et al. 2013) in R ( $\mathrm{R}$ Development Core Team 2012).

\section{Demographic vulnerability mapping}

The demographic vulnerability index was used to assess a population's risk of extirpation from demographic stochasticity resulting from small population size and low immigration (Mills 2007). We characterized demographic vulnerability for each population based on three metrics, which provided estimates of the demographic status within populations, between populations, and over time (Fig. 2): (1) abundance (census size) within populations, (2) number of immigrants from other populations (strayers), and (3) change in abundance in populations.

Abundance is a direct measure of the status of a population and is generally the preferred metric used to determine whether populations are declining (IUCN 2010). Therefore, we used the total number of individuals $N_{j}$ (after migrants returned to their natal populations and strayers immigrated to their new populations) as the first demographic metric for each population $j$. CDFISH tracks the number of immigrants $M_{j}$ into each population $j$, which was used as the second demographic metric. We assumed that immigrants increased the probability of population persistence by providing a demographic subsidy (e.g., demographic rescue, Levins 1969, Brown and Kodric-Brown 1977, Garant et al. 2007). As with the genetic vulnerability index, the metrics $N$ and $M$ give a snapshot of spatial variation in population demographics. Therefore, we measured the temporal demographic vulnerability for population $j$ as the change in abundance $\left(\Delta N_{j t}\right)$ from the initial level of abundance as $N_{j t}-N_{j t 0}$.

As was the case for $G_{\mathrm{v}, j t}$, we normalized each demographic vulnerability metric between 0 and 1 using the following linear transformations and assumed equal weights. First, the domain of abundance $(N)$ is between 


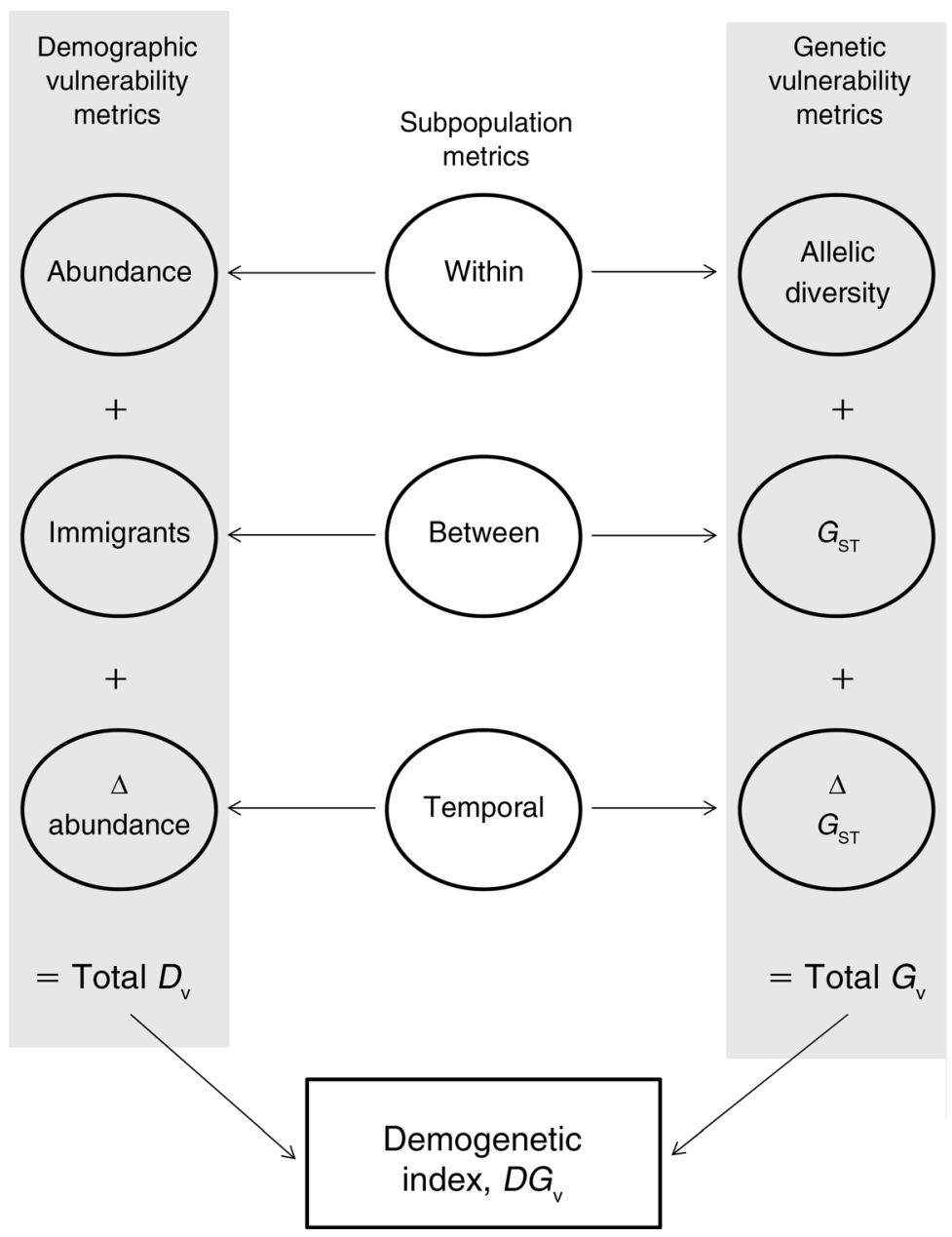

FIG. 2. Demogenetic vulnerability flow diagram. The three genetic metrics (allelic diversity, differentiation $\left[G_{\mathrm{ST}}\right]$, and change in differentiation $\left[\Delta G_{\mathrm{ST}}\right]$ ) and the three demographic metrics (abundance, immigrants, and change $[\Delta]$ in abundance) that reflect within, between, and temporal population vulnerability (through demographic vulnerability $\left[D_{\mathrm{v}}\right]$ and genetic vulnerability $\left[G_{\mathrm{v}}\right]$ ) are added together to produce demogenetic vulnerability indices $\left(D G_{\mathrm{v}}\right)$.

0 and $K$, the carrying capacity, so $N$ was normalized by $K$. A higher $N$ is considered positive for a population; therefore, a large number of individuals returning to their respective population corresponds to a low vulnerability value. Second, the domain of number of immigrants $(M)$ lies between 0 and $K(n-1)$ probability of straying ( 9.0 in these simulations, from $n=19$ populations, $K=50$, and 0.01 probability of straying). Instead of $K$, we chose $N_{j t}$ to normalize $M$, which allowed us to also compare the relative contribution of immigrants vs. nonimmigrants within a population $j$ at given $t$. Immigration is considered positive for a population; therefore, high amounts of immigration produce a lower vulnerability index. Finally, the domain of $\Delta N$ is $[-K, K]$, so we normalized by $K$. Any positive change (increase) in abundance from the initial generation $t_{0}$ is considered positive for a population and, therefore, given a value of 0.0. Any negative change in abundance (a loss of individuals from initial abundance numbers) is considered negative, resulting in an increase in the vulnerability metric.

Accordingly, the demographic vulnerability index for a particular population at a given generation becomes

$$
\begin{aligned}
D_{\mathrm{v}, j t}= & \left(-\frac{N_{j t}}{K_{j}}+1\right)+\left(-\frac{M_{j t}}{N_{j t}}+1\right) \\
& +\left(\begin{array}{c}
0, \Delta N_{j t}>0 \\
-\frac{\Delta N_{j t}}{K_{j}}, \Delta N_{j t} \leq 0
\end{array}\right) .
\end{aligned}
$$

$D_{\mathrm{v}, j t}$ becomes an estimate for the state of a population's demographic vulnerability. The three normalized metric values are added together, allowing $D_{\mathrm{v}, j t}$ to range between 0 and 3 , where $D_{\mathrm{v}, j t}=0$ is the minimal demographic vulnerability and $D_{\mathrm{v}, j t}=3$ is the maximum possible vulnerability for a population. 


\section{Demogenetic vulnerability mapping}

A demogenetic vulnerability index $D G_{\mathrm{v}, j t}$ can then be defined as the mean of Eq. 5 and Eq. 6, or $D G_{\mathrm{v}, j t}=\left(G_{\mathrm{v}, j t}\right.$ $\left.+D_{\mathrm{v}, j t}\right) / 2$, based on an equal weighting scheme that can be easily modified (e.g., Whited et al. 2012). We tracked the individual metrics contributing to both the demographic and genetic vulnerability indices, as well as the demogenetic vulnerability index for the four scenarios. Each index was plotted across 75 generations to show temporal differences.

\section{Pilot application to bull trout}

We used the CDFISH program to assess how increasing stream resistance influenced indices of population vulnerability in a realistic network of migratory and resident bull trout populations. This empirical pilot study complements our hypothetical example by adding more realistic bull trout simulation parameters for temporal modeling to assess effects of future temperature increases on vulnerability, and by using more populations, which are initially parameterized using real demographic data (redd counts per population). Spatial locations and structure were based on the configuration of 28 bull trout populations in the same upper Flathead River basin (Fig. 3), but expanded into Glacier National Park, Montana (GNP). We considered two scenarios: (1) a current stream temperature resistance to movement on which population dynamics were projected for the next 100 years, and (2) a projected future stream temperature resistance to movement on which population dynamics were projected for the next 100 years.

We used the same model of stream temperature for the Flathead system (Jones et al. 2014), and modeled a probability of occurrence in response to temperature, following Wenger et al. (2011). Average stream temperatures under a current conditions scenario (1980-2000; Jones et al. 2013) and a future conditions scenario (20202040 [Mote and Salathe 2009]; Fig. 3) were inserted into the Wenger et al. (2011) probability of occurrence equation for bull trout (using stream temperature and slope as occurrence parameters). These surfaces were then transformed using the inverse logit transformation and scaled to produce resistance surface values between 1.0 and 2.0. Following our previous work, UNICOR was used to compute a matrix of cost-to-movement between all pairs of populations on the riverscape for each resistance surface. Cost distance values from all populations to the lake source are shown in Table 2.

We specified carrying capacities and initialized each population based on empirical bull trout population data collected from 1980 to 2012 in the upper Flathead system (i.e., redd counts). Redd abundances are significantly correlated with salmonid spawner abundance (Rieman and Allendorf 2001) and are commonly used to estimate abundance and distribution of local and regional bull trout populations (Rieman and Myers 1997, Muhlfeld et al. 2006). Carrying capacity was set as the maximum observed abundance for each population, and each population was initialized using the abundance estimates in 2012 (Downs et al. 2006, Weaver 2006; Montana Fish, Wildlife and Parks, T. Weaver, unpublished data; Glacier National Park, C. Downs, unpublished data). Redd count data were unavailable for several populations in GNP prior to the invasion of nonnative lake trout (Salvelinus namaycush), which have caused substantial population declines, so we used an estimate obtained for a nonimpacted lake population (Quartz Lake, $n=150$ adults) as the carrying capacity for these populations.

We specified overlapping generations and a 3:1 male to female sex ratio (Fraley and Shepard 1989). We chose a polygamous random mating structure within populations, where each male could mate randomly (with replacement) with more than one female. Each mated female produced a constant number of offspring of 4500 (Fraley and Shepard 1989, Downs et al. 2006). Offspring death rate was then set to $99 \%$ with $33 \%$ female survival to ensure the $3: 1$ sex ratio, and adult mortality was set to 50\% (Fraley and Shepard 1989, Downs et al. 2006).

We lacked genetic data for the entire system and so followed a burn-in procedure similar to the generic simulations previously described, setting equal probabilities of migration and straying for each subpopulation for 10 years to establish a genetic burn-in pattern with 20 initial independent loci and 20 random alleles per locus. After this burn-in period, our initial 28 populations had a total of 400 alleles (with each population mean expected and observed heterozygosity of approximately 0.91 and 0.92 , equivalently, and 355 alleles, on average). The temperature resistance scenarios were then used for an additional 100 generations to determine increasing or decreasing population sizes resulting from a combination of individual migratory behaviors and the dynamics of population vital rates.

We modeled three distinct life-history strategies exhibited by bull trout populations in the upper Flathead River and Lake system and GNP. As noted above, bull trout juveniles can either reside in the local population or migrate to a lake to grow to maturity. For all populations with a dominant migratory strategy to Flathead Lake, the probability of residency was set to 0.05. For populations that spend their entire life cycle within glacial lake drainages in GNP (populations 1823 ), we used a residency probability of 0.95 to allow for some degree of dispersal among populations. For two populations isolated upstream of waterfall barriers in GNP (26 and 27), we set the residency probability to 1.0 to account for these dispersal barriers. Offspring that migrated to connected lakes were allowed to either migrate back to their natal stream population, stray (i.e., disperse) to a different population (a 0.01 probability in these simulations, except in the completely resident populations), or die. Resident and straying probabilities for each population are shown in Table 2.

For temperature scenario 1, the movement cost function was scaled between the minimum cost distance 


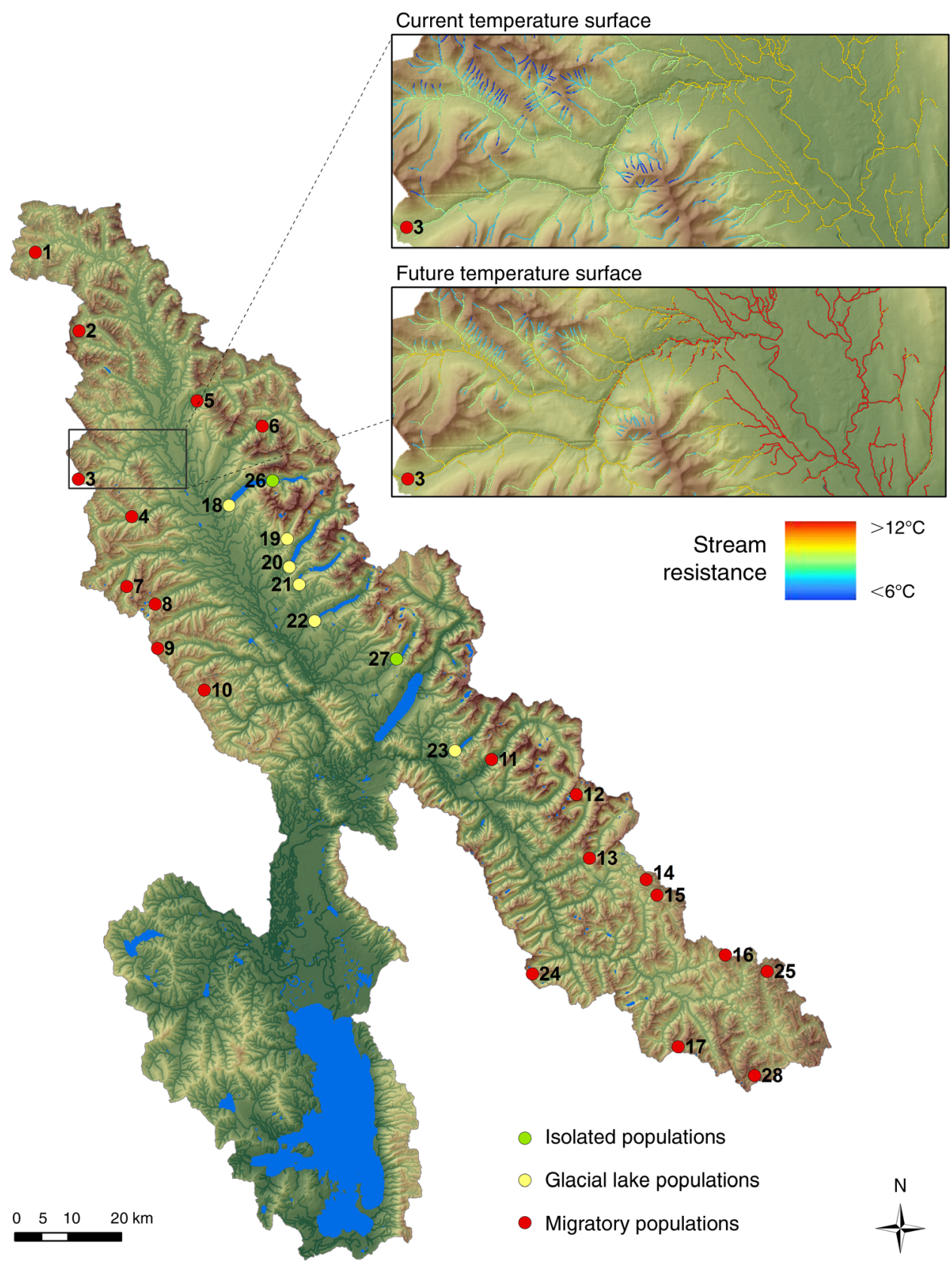

FIG. 3. Study area for pilot project, with 28 bull trout populations. The right inset illustrates the two temperature resistance surface scenarios used: current conditions scenario (upper box, 1980-2000; Jones et al. 2014) and future conditions scenario (lower box, 2020-2040; Mote and Salathe 2009). Average stream temperatures for each scenario were inserted into the Wenger et al. (2011) probability of occurrence equation for bull trout, transformed using the inverse logit transformation, and scaled to produce resistance surface values between 1.0 and 2.0. Migratory populations are those populations of bull trout that migrate from their natal streams to Flathead lake to grow to maturity, and then return to spawn; glacial lake populations are those bull trout that spend their entire life cycle in one drainage; and isolated populations are those populations that are cut off from other drainages or streams by physical barriers.

and the maximum cost distance on the current riverscape resistance surface (1980-2000; see Table 2). Thus, as temperatures increased in scenario 2 under future climate warming predictions (2020-2040), the probability of movement decreased; if the cost distance was greater than the maximum migration distance, then the probability of movement was set to 0.0 . All probability values for fish migrating back to natal streams are shown in Table 2.

The current riverscape resistance surface was run for 100 years in scenario 1. To test for the effect of increasing stream temperature on demogenetic indices 
TABLE 2. Carrying capacities $(K)$, initial abundance $\left(N_{j t 0}\right)$, residency probabilities (Res), straying probabilities (Stray), as well as cost distance (Cost) and respective functional probability values (Prob.) under current and future temperature conditions for each population of bull trout under study.

\begin{tabular}{|c|c|c|c|c|c|c|c|c|}
\hline \multirow[b]{2}{*}{ Population } & \multirow[b]{2}{*}{$K$} & \multirow[b]{2}{*}{$N_{j t 0}$} & \multirow[b]{2}{*}{ Res } & \multirow[b]{2}{*}{ Stray } & \multicolumn{2}{|c|}{ בCurrent temp. surface } & \multicolumn{2}{|c|}{ Future temp. surface } \\
\hline & & & & & Cost & Prob. & Cost & Prob. \\
\hline 1 & 323 & 51 & 0.05 & 0.01 & 331741 & 0.00 & 390010 & 0.00 \\
\hline 2 & 339 & 29 & 0.05 & 0.01 & 297490 & 0.23 & 352889 & 0.00 \\
\hline 3 & 77 & 0 & 0.05 & 0.01 & 281892 & 0.33 & 335692 & 0.00 \\
\hline 4 & 323 & 38 & 0.05 & 0.01 & 257022 & 0.49 & 308279 & 0.15 \\
\hline 5 & 19 & 3 & 0.05 & 0.01 & 271832 & 0.40 & 325425 & 0.04 \\
\hline 6 & 74 & 48 & 0.05 & 0.01 & 266565 & 0.43 & 319157 & 0.08 \\
\hline 7 & 966 & 115 & 0.05 & 0.01 & 252073 & 0.53 & 301967 & 0.20 \\
\hline 8 & 61 & 0 & 0.05 & 0.01 & 234043 & 0.64 & 281513 & 0.33 \\
\hline 9 & 387 & 96 & 0.05 & 0.01 & 225647 & 0.70 & 270736 & 0.40 \\
\hline 10 & 243 & 51 & 0.05 & 0.01 & 203050 & 0.85 & 244824 & 0.57 \\
\hline 11 & 86 & 45 & 0.05 & 0.01 & 191179 & 0.93 & 232159 & 0.66 \\
\hline 12 & 278 & 48 & 0.05 & 0.01 & 237254 & 0.62 & 284010 & 0.31 \\
\hline 13 & 170 & 170 & 0.05 & 0.01 & 230586 & 0.67 & 277035 & 0.36 \\
\hline 14 & 74 & 42 & 0.05 & 0.01 & 251887 & 0.53 & 300013 & 0.21 \\
\hline 15 & 144 & 144 & 0.05 & 0.01 & 272443 & 0.39 & 322408 & 0.06 \\
\hline 16 & 349 & 234 & 0.05 & 0.01 & 280956 & 0.34 & 331413 & 0.00 \\
\hline 17 & 230 & 70 & 0.05 & 0.01 & 290737 & 0.27 & 341721 & 0.00 \\
\hline 18 & 150 & 0 & 0.95 & 0.01 & 241138 & 0.60 & 291294 & 0.27 \\
\hline 19 & 150 & 16 & 0.95 & 0.01 & 227089 & 0.69 & 273832 & 0.38 \\
\hline 20 & 150 & 10 & 0.95 & 0.01 & 221722 & 0.73 & 268908 & 0.41 \\
\hline 21 & 150 & 115 & 0.95 & 0.01 & 211000 & 0.80 & 255777 & 0.50 \\
\hline 22 & 150 & 3 & 0.95 & 0.01 & 202293 & 0.85 & 245667 & 0.57 \\
\hline 23 & 150 & 3 & 0.95 & 0.01 & 180157 & 1.00 & 219072 & 0.74 \\
\hline 24 & 83 & 83 & 0.05 & 0.01 & 252867 & 0.52 & 301401 & 0.20 \\
\hline 25 & 301 & 45 & 0.05 & 0.01 & 317443 & 0.09 & 369537 & 0.00 \\
\hline 26 & 150 & 80 & 1.0 & 0.00 & 253229 & 0.52 & 305261 & 0.17 \\
\hline 27 & 150 & 115 & 1.0 & 0.00 & 210942 & 0.80 & 256048 & 0.50 \\
\hline 28 & 166 & 16 & 0.05 & 0.01 & 316255 & 0.10 & 368187 & 0.00 \\
\hline Mean & 210 & 56 & & & 250376 & 0.54 & 299080 & 0.25 \\
\hline $\mathrm{SD}$ & 175.3 & 56.4 & & & 39201.0 & 0.259 & 43343.2 & 0.227 \\
\hline
\end{tabular}

Note: Functional probabilities are based on a linear function scaled to the minimum and maximum cost distance values in the current temperature stream network (populations 23 and 1, respectively).

in scenario 2, we ran the current riverscape resistance surface for $40 \mathrm{yr}$, and then the future riverscape resistance surface (2020-2040) was inserted and run for an additional $60 \mathrm{yr}$. We performed 100 independent Monte Carlo replicates to quantify the variability in population dynamics and spatial genetic structure.

\section{RESUlts}

\section{Genetic vulnerability metrics}

We computed the three genetic vulnerability metrics for all populations (Appendix: Table A1) for each of our four scenarios and for (1) generation 0 (the initial burnin generation), (2) generation 1 (first generation after insertion of the riverscape resistance surface), (3) generation 55 (the first generation in which both populations 19 and 11 go extinct across all 100 simulation replicates, and (4) generation 75 (the final generation in the simulations). We plotted the mean of the 100 replicates for each metric and the four scenarios across the 75 generations (Fig. 4). Allelic diversity within populations decreased through time, because allelic diversity is sensitive to local $N$ and total $N$ (discussed in Demographic vulnerability metrics; Appendix: Table A2). Mean pairwise $G_{\text {ST }}^{\prime}$ (for focal populations) tended to increase initially and then decrease, due to decreasing heterozygosity with increasing differentiation $\left(G_{\mathrm{ST}}\right)$, which causes $G_{\mathrm{ST}}^{\prime}$ to decrease. This was true in all populations, except for a constant increase toward 1.0 in population 12 (scenario 4 ), the completely isolated resident population, as well as populations 19 and 11 (scenarios 2 and 3, respectively) that went extinct. Temporal genetic differentiation values are small and nearly mimic $G_{\mathrm{ST}}^{\prime}$ behavior in all populations.

\section{Demographic vulnerability metrics}

Means of each demographic metric for the 100 replicates and the four scenarios across the 75 generations are plotted in Fig. 5 with numerical results for the four generations presented in the Appendix: Table A2. Abundance $(N)$ for all populations was 50 individuals at generation 0 and dropped globally by $50 \%$ after generation 1 , stabilizing to $\sim 40 \%$ of the entire population at around generation 15 (Appendix: Table A2). In generation 1, the values for $N$ showed an immediate response to the changing riverscape surface in the partial isolation and maximum resistance scenarios (populations 11 and 19, respectively). The resident-only population 12, representing complete isolation (Fig. 5d), maintained carrying capacity throughout the simulations $(\Delta N=0)$ because individuals were not influenced by the riverscape resistance surface. Abun- 


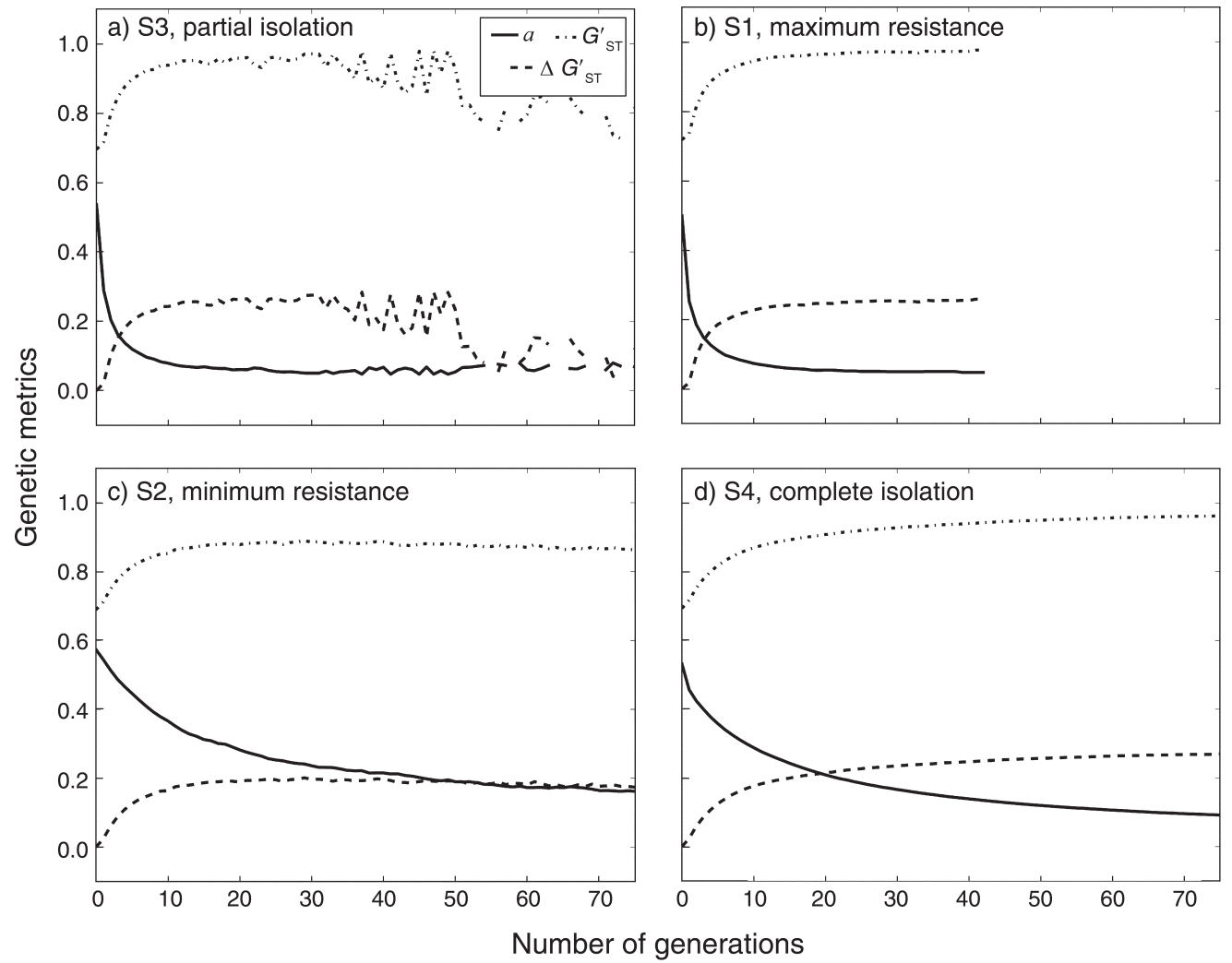

FIG. 4. Genetic vulnerability metrics within the four scenarios; (a) partial isolation, (b) maximum resistance, (c) minimum resistance, and (d) complete isolation. Allelic diversity ( $a$, solid lines), genetic differentiation ( $G^{\prime}$ ST, dash-dotted lines), and temporal genetic differentiation $\left(\Delta G^{\prime}\right.$ ST, dashed lines) are shown across 75 generations and a mean of 100 replicates.

dance was also maintained in population 9 (scenario 2; Fig. 5c). Population 19 (scenario 1; Fig. 5b) received no strayers and was the first to go extinct (in generation 43 in all replicates). Population 11 (scenario 3; Fig. 5a) first went extinct in generation 55, but was periodically recolonized by small numbers of immigrants from surrounding populations in subsequent generations.

Straying was capped at a probabilistic draw of 0.01 of the total abundance in a population at a given generation (except population 12 received no strays), which is a direct result of the life history-based simulation parameters (see Discussion). Consequently, most $M_{j}$ reflected low metric values relative to $N_{j}$, except in population 11 (Fig. 5a), where recolonization events tended to dominate the population dynamics in later generations $(>50)$. Change in abundance was plotted as the difference from the initial time and had small values throughout the generations for the two stable demographic populations (scenario 2, Fig. 5c; scenario 4, Fig. $5 \mathrm{~d}$ ), but increased significantly for the non-stable demographic populations (scenario 1, Fig. 5b; scenario 3, Fig. 5a).

\section{Demogenetic vulnerability indices}

The mean of the replicates for each demogenetic index are plotted for the four scenarios across 75 generations in Fig. 6 (Appendix: Table A3 displays the values). At spatial genetic burn-in, mean vulnerability maps show low variability among populations, with indices for genetic, demographic, and demogenetic vulnerability of $1.15 \pm 0.54$ (mean \pm SD), $0.99 \pm$ 0.010 , and $1.07 \pm 0.028$, respectively (Appendix: Table A3). Consistent with the individual demographic metrics, $D_{\mathrm{v}}$ was most sensitive initially to the riverscape surface for the two non-stable populations, 11 and 19 (Fig. 6a, b; dash-dotted lines), tracking initial population fluctuations (Fig. 5a, b; dash-dotted lines), and showed the highest values (increased to a maximum value of 3.0) as compared to the two stable population scenarios, 9 and 12 (stabilized at 1.0 or near the initial spatial genetic burn-in values).

$G_{\mathrm{v}}$ was not influenced by these initial perturbations after the riverscape resistance surface was introduced, but rather increased more gradually through time. In general, $G_{\mathrm{v}}$ values were consistently smaller for population 9 (Fig. 6c) and for the fluctuating population 11 (Fig. 6a) only when abundance was low and immigrants began to dominate the metrics (generation $>40$ ). $G_{\mathrm{v}}$ values were generally higher for populations 19 (Fig. 6b) and 12 (Fig. 6d). Demogenetic vulnerability $\left(D G_{\mathrm{v}}\right)$ is plotted as the average in Fig. 6. 


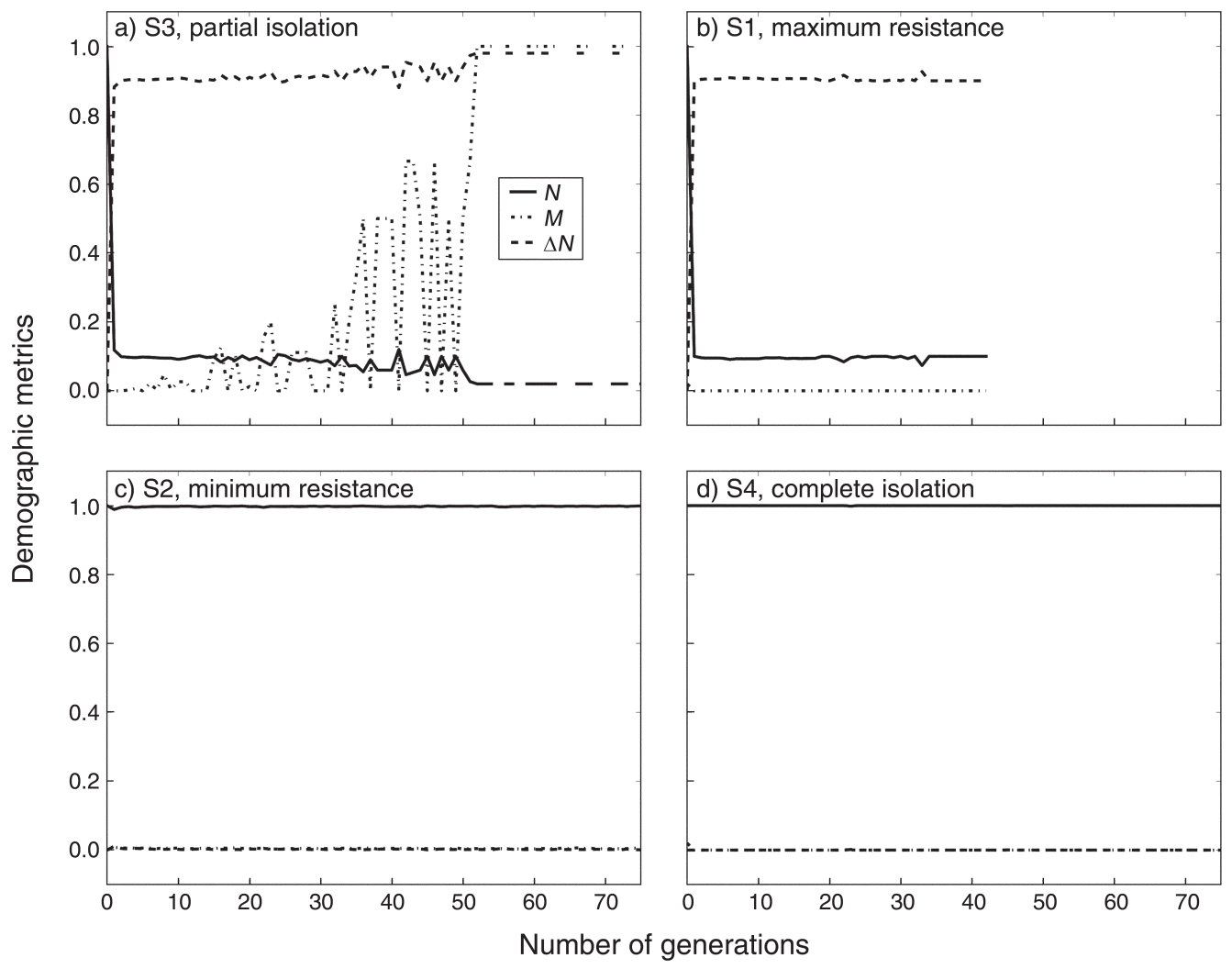

FIG. 5. Demographic vulnerability metrics within the four scenarios (as in Fig. 4). Abundance ( $N$, solid lines), number of immigrants ( $M$, dash-dotted lines), and absolute value of change in abundance ( $\Delta N$, dashed lines) are shown across 75 generations and a mean of 100 replicates.

\section{Pilot application to bull trout}

The mean probability of an individual migrating from the lake back to its natal population under current and future temperature surfaces was 0.54 (range $=0.0-1.0$, $\mathrm{SD}=0.259)$ and 0.25 (range $=0.0-0.74, \mathrm{SD}=0.25)$, respectively (Table 2). As expected, individuals that migrated greater distances (to more distant populations) typically had the largest cost to movement (resistance to migration) due to accumulated costs of migrating through more water with warmer temperatures. For example, in scenario 1 (current resistance surface) the population located farthest from Flathead Lake (population 1) had a probability of receiving returning individuals of 0.0. Populations that exceeded this costto-movement threshold in scenario 2 (future climate warming) also had a probability of receiving returning individuals of 0.0 (Table 2). Population 23 had the smallest cost to movement for migrating individuals in scenario 1 and a probability of 1.0, which resulted in all individuals returning from the lake and remaining near full carrying capacity. However, for this population in scenario 2 , the probability of an individual migrating from the lake decreased to 0.74 following increased resistance due to increased water temperature.

The resulting demographic and genetic vulnerability indices for each scenario are plotted in Fig. 7. Five populations are highlighted to contrast results. Population 1 , which had the maximum cost to movement in scenario 1 (dash-dotted line), exhibited both the highest $G_{\mathrm{v}}$ and $D_{\mathrm{v}}$ indices. Population 28 (triangles), also at the extremity of the riverscape, had a 0.10 probability of receiving migrating individuals in scenario 1 and closely followed population 1's values (especially with $G_{\mathrm{v}}$ ). Another notable population in scenario 1 is population 7 (dashed line), which had a relatively low probability of returning migrants $(0.34)$ but the highest carrying capacity $(K=966)$. As a result, it maintained the lowest $G_{\mathrm{v}}$ compared to the rest of the populations, while $D_{\mathrm{v}}$ declined to an average level among the other populations. All of the GNP populations (complete or partially isolated with some migration allowed) behaved similarly, as expected from the previous results with completely resident populations; $G_{\mathrm{v}}$ increased steadily and $D_{\mathrm{v}}$ dropped dramatically to the lowest value of 1.0 (for example, population 26, plotted as a solid line).

After year 40 , the influence of the future riverscape resistance surface on demogenetic indices is seen in the second column in Fig. 7. The two extremity populations (1, dash-dotted; 28, triangles) continue to show the highest $G_{\mathrm{v}}$ values and relatively high $D_{\mathrm{v}}$ values, although other populations became more demographically vulnerable (e.g., population 15; circles). Populations 3, 8, 
a) S3, partial isolation

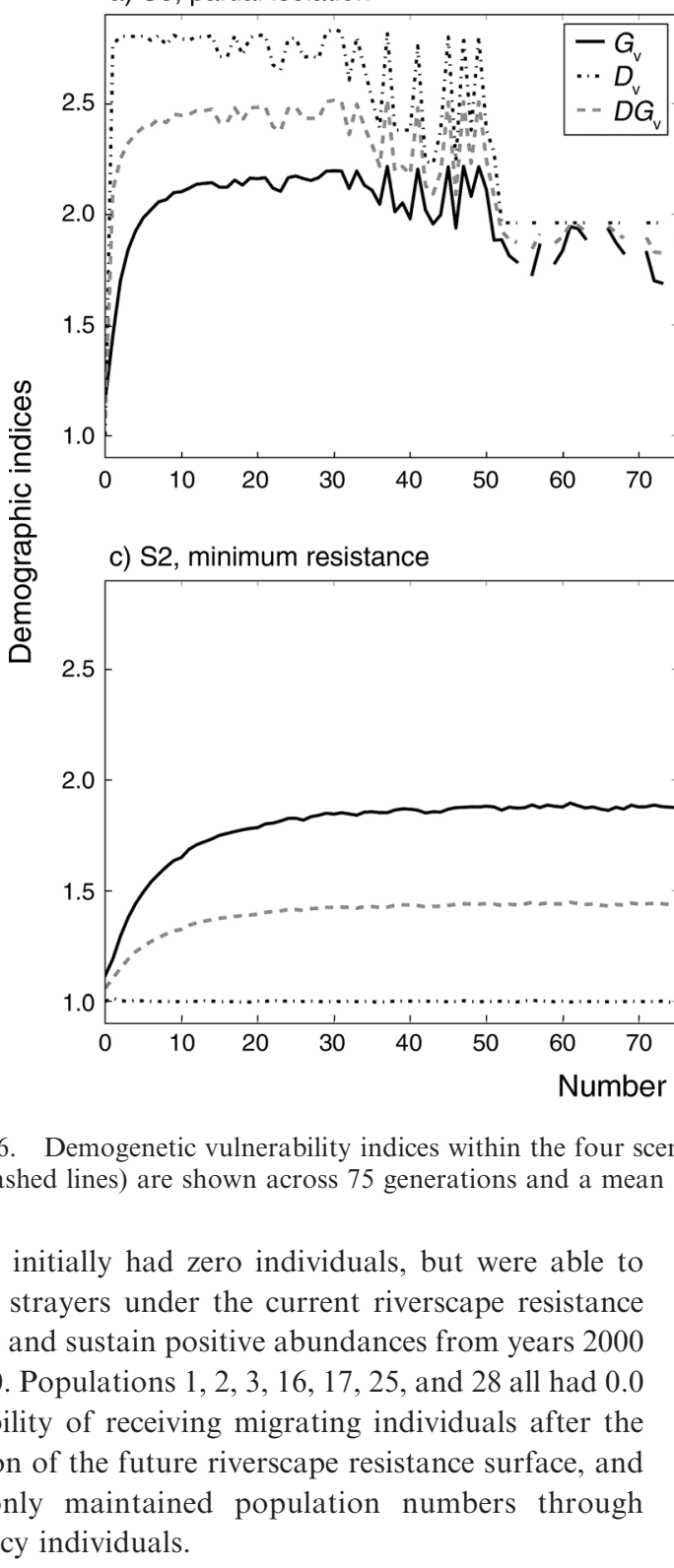

b) S1, maximum resistance

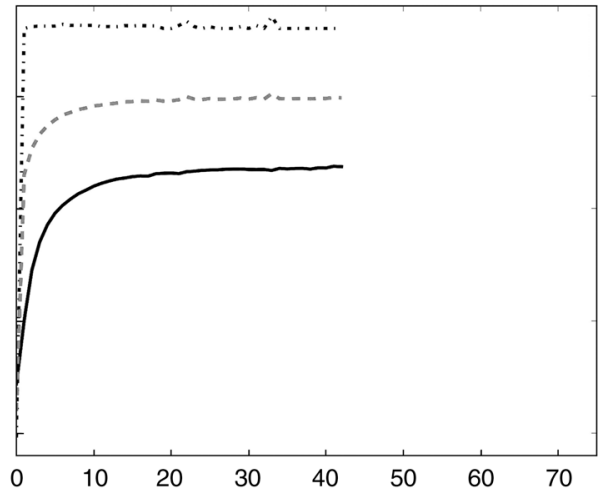

d) $\mathrm{S} 4$, complete isolation

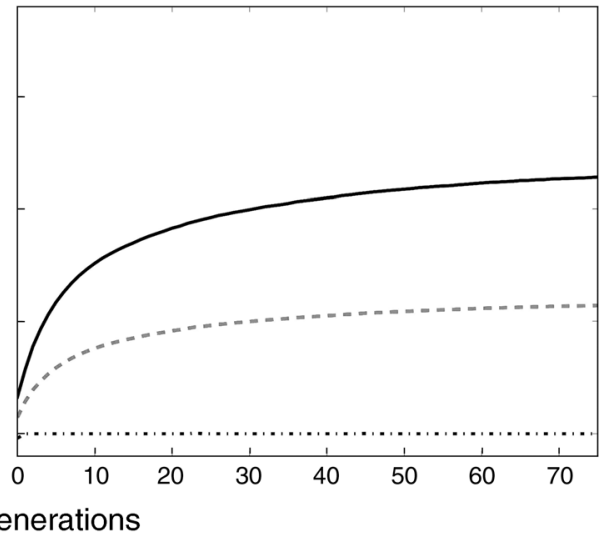

FIG. 6. Demogenetic vulnerability indices within the four scenarios (as in Fig. 4). $G_{\mathrm{v}}$ (solid lines), $D_{\mathrm{v}}$ (dash-dotted lines), and

\section{Discussion}

Hypothetical modeling scenarios. Our hypothetical modeling scenarios illustrate the usefulness of a demogenetic resistance modeling framework to identify populations vulnerable to environmental change and reduced connectivity within riverscapes. Specifically, our hypothetical and empirically based modeling scenarios show that warmer water temperatures and/or physical or hydrological barriers (e.g., low flows or dewatering) to movement (or the cumulative effect of distance traveled through these environments) are predicted to fragment suitable habitat for migratory salmonids, resulting in the potential loss of genetic diversity within populations and reduced population sizes.

and 18 initially had zero individuals, but were able to surface and sustain positive abundances from years 2000 to 2040. Populations 1, 2, 3, 16, 17, 25, and 28 all had 0.0 probability of receiving migrating individuals after the thus only maintained population numbers through residency individuals.

(s)
vulnerability response of resistance to movement was a
function of stream temperature over extended river distance, plus an imposed current barrier. The population showed low genetic vulnerability due to occasional gene flow (infusion of immigrants) from nearby populations, and relatively high demographic vulnerability as a result of low population abundance due to the imposed barrier. In scenario 4 (complete isolation), resistance to movement was not assessed, but instead a complete resident population was simulated (i.e., mimicking a long-term impediment that caused separation). The population responded with high genetic vulnerability due to a lack of genetic exchange with 
a) $G_{v}$, current temperature

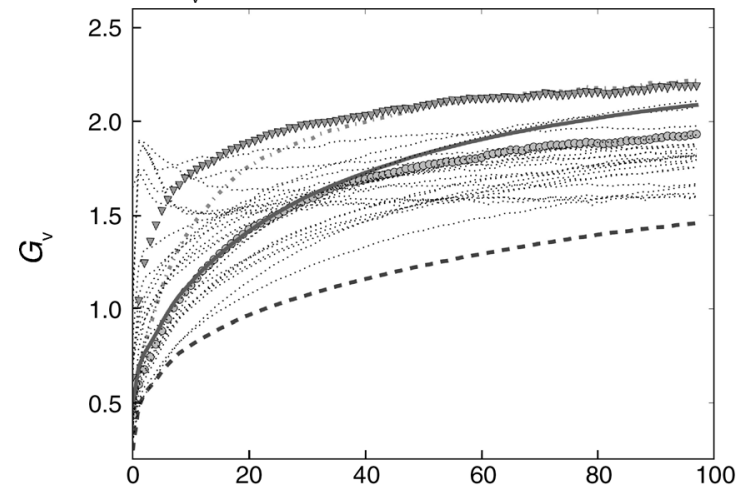

c) $D_{v}$, current temperature

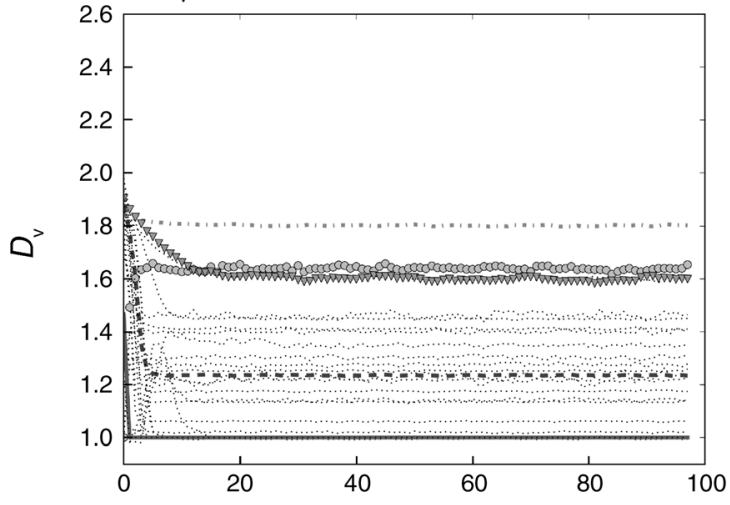

b) $G_{v}$, future temperature

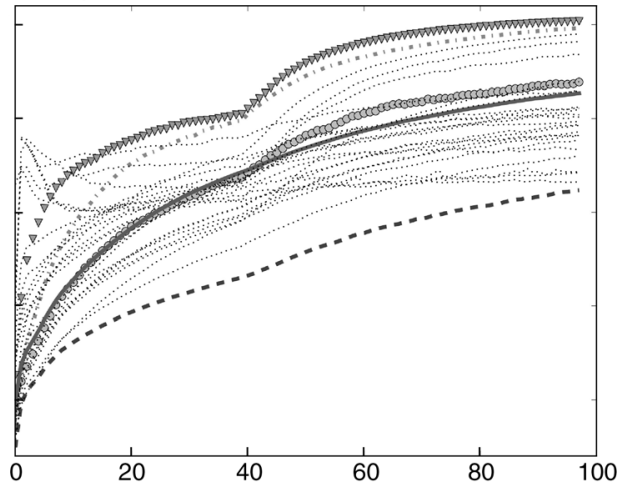

d) $D_{v}$, future temperature

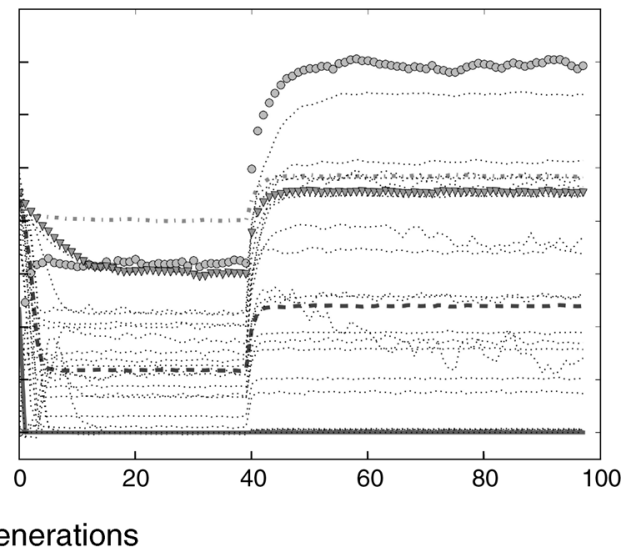

FIG. 7. Demogentic vulnerability indices for bull trout populations. All 28 populations are plotted for 100 generations (years) for (a) $G_{\mathrm{v}}$ with the current temperature surface, (b) $G_{\mathrm{v}}$ with a modeled future temperature surface, (c) $D_{\mathrm{v}}$ with the current temperature surface, and (d) $D_{\mathrm{v}}$ with the future temperature surface. Population 1 (maximum cost to movement in scenario 1; dashdotted line) exhibits the highest $G_{\mathrm{v}}$ and $D_{\mathrm{v}}$ indices. Another notable population in scenario 1 is population 7 (dashed line), which had a relatively low probability of returning migrants $(0.34)$ but the highest carrying capacity $(K=966)$. As a result, it maintained the lowest $G_{\mathrm{V}}$ compared to the rest of the populations, while $D_{\mathrm{v}}$ declined to an average level compared to the other populations. Population 15 (circles) became more demogenetically vulnerable. Population 26 (solid line), shows the typical pattern for completely or partially isolated populations; $G_{\mathrm{v}}$ increases steadily and $D_{\mathrm{v}}$ drops dramatically to the lowest value of 1.0 . Population 28 (triangles), also at the extremity of the riverscape, had a 0.10 probability of receiving migrating individuals in scenario 1 and closely followed population 1's values (especially with $G_{\mathrm{v}}$ ). All populations are shown with a mean of 100 replicates.

other populations, and low demographic vulnerability caused by a relatively large population size of resident individuals despite the lack of immigration. These modeling scenarios can be modified to encompass a range of life-history strategies and management issues in freshwater systems, including climate change, habitat degradation and fragmentation, invasive species, and isolation management (e.g., creation of a barrier to isolate a population and prevent invasions by nonnative species; Fausch et al. 2009).

\section{Vulnerability metrics}

We present three important genetic metrics (diversity, differentiation, and change in differentiation) to assess genetic vulnerability within and among populations (Fig. 2). Genetic diversity within a population is measured by assessing allelic diversity, which is more sensitive than heterozygosity $\left(H_{\mathrm{e}}\right)$ for early detection of population declines, differentiation or isolation (Leberg 1992, Luikart et al. 1998). Likewise, $G_{\mathrm{ST}}$ is a widely used measure of genetic differentiation (Hedrick 2005). Nonetheless, this metric could be replaced with any other estimator of differentiation, such as $D_{\text {est }}$ (Jost 2008), or an estimator of current (real time) gene flow (e.g., Wilson and Rannala 2003). The third metric, temporal change in genetic differentiation $\left(G_{\mathrm{ST}}\right)$, was chosen because a temporal increase in $G_{\mathrm{ST}}$ signals rapid isolation and a likely decrease in the local effective population size, which increases fixation of deleterious alleles and extinction risk (e.g., Allendorf and Luikart 2007). Large decreases in genetic differentiation could also be detrimental, indicating homogenization and loss of local adaptations (e.g., Ryman et al. 1995). Therefore, in our simulations, any temporal change in $G_{\mathrm{ST}}$ 


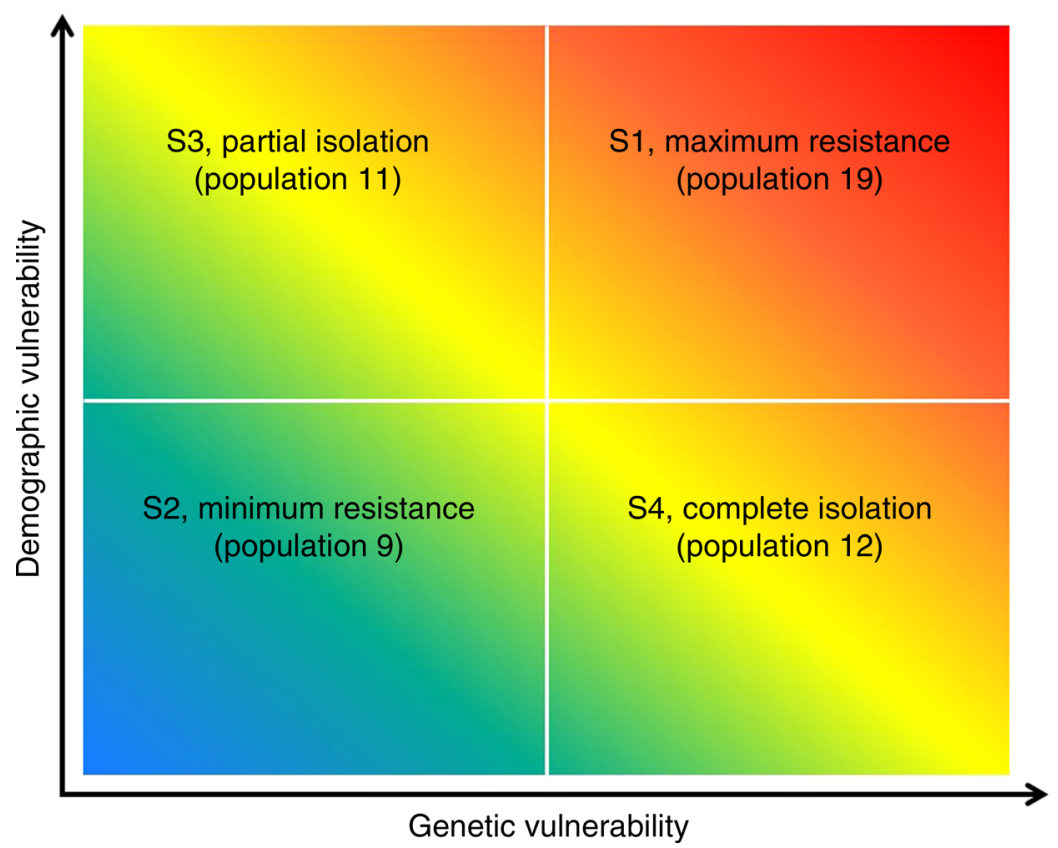

FIG. 8. Genetic vulnerability vs. demographic vulnerability, plotted as population response in certain studied populations with respect to riverscape resistance and life-history strategies from low to high vulnerability. Blue is low vulnerability and red is high vulnerability. Partial isolation (scenario 3) populations showed low genetic vulnerability (due to occasional immigrants) and high demographic vulnerability (due to low population abundance from the imposed barrier). Maximum resistance (scenario 1) populations revealed both high genetic and demographic vulnerability. Minimum resistance (scenario 2) populations responded with both low genetic and demographic vulnerability. Complete isolation (scenario 4) populations showed high genetic vulnerability (due to a lack of genetic exchange with other populations) and low demographic vulnerability (caused by a relatively large population size of resident individual despite the lack of immigration).

contributed to the overall genetic vulnerability index. Here again, however, the vulnerability index can easily be adjusted to reflect different patterns of genetic effect, such as negative effects of only temporal declines in $G_{\mathrm{ST}}$.

Other genetic metrics sensitive to population fragmentation and decline are estimators of the effective population size $\left(N_{\mathrm{e}}\right.$, per generation), the effective number of breeders (per year), and bottleneck tests (Luikart et al. 1999, Waples and Do 2009, England et al. 2010). Future work is needed to assess the sensitivity of different combinations of these metrics to a set of standardized scenarios. Also, because it is now feasible to genotype hundreds or thousands of loci in any species (Allendorf et al. 2010), simulations could be used to test if certain indices become more sensitive with increasing number of loci (e.g., Waples and Do 2010).

We present three demographic metrics (abundance, immigration, and change in abundance) that reflect within- and between-population parameters (Fig. 2). These metrics are widely used to assess population dynamics and viability in wild populations (Mills 2007). These metrics (including within- and between-population metrics) also provide symmetry with the three genetic metrics. A combination of demographic and genetic metrics should assure early detection of vulnerability, and may also facilitate a better understanding of the potential causes and consequences of vulnerability and population declines. For example, our simulations suggest that partial barriers may be more likely to pose a demographic risk (scenario 3), whereas complete barriers are more likely to pose a genetic risk (scenario 4). However, it is important to note that the risks imposed by a partial barrier will be highly dependent on the location of the barrier within the larger river network, and the interaction with the underlying resistance surface (Grant et al. 2007). Other demographic factors to consider in future research include estimates of the number of effective breeders, emigration rates, and temporal variation in the number of immigrants and emigrants. These types of data are readily available in many cases using conventional and novel methods for marking and tracking individual fish (e.g., capturemark-recapture, telemetry, otolith chemistry, and genetics).

\section{Modeling framework applications}

Our demogenetic vulnerability modeling framework can be used to understand connectivity and genetic diversity of populations across diverse habitats to restore, maintain, and monitor adaptive potential of aquatic species (Lowe and Allendorf 2010, Schindler et al. 2010). Many freshwater fishes, particularly salmonids, exhibit complex movements among spawning, feeding, and survival habitats in stream networks 
(Northcote 1997), and occur in subpopulations linked by immigration and emigration (i.e., metapopulations; Hanski and Gilpin 1991). Demographic and genetic traits of fish populations, therefore, often vary spatially and temporally within and among watersheds, reflecting major genetic differences and adaptations imposed by local environments (Hitt and Roberts 2012). Our demogenetic vulnerability modeling framework can be used to identify conservation units that maximize genetic diversity, potential for local adaptation, and population abundance in freshwater systems.

This framework can also be used to assess the potential impacts of climate warming (e.g., increased stream temperatures and decreased flows) on freshwater fishes and critical habitats, as we have demonstrated with the empirical analysis on bull trout populations. Although broad-scale bioclimatic assessments have been valuable for raising awareness about the risks posed by climate change (Wenger et al. 2011, Isaak et al. 2012, Jones et al. 2014), predictions often lack the spatial and temporal resolution that managers need to prioritize habitat restoration opportunities within river networks. Moreover, most bioclimatic modeling efforts have focused on distributional patterns (i.e., occurrence), ignoring critical components of population persistence, such as demography and genetics. Our approach allows for fine-scale, spatially explicit vulnerability assessments at scales relevant to management needs (i.e., reach and stream scales), and moves beyond bioclimatic niche assessments by integrating additional measures affecting population persistence, genetics and demography, both of which are necessary to develop accurate and comprehensive vulnerability assessments for aquatic species. For example, results can be visualized using heat maps (Fig. 9), which identify populations that are predicted to be the most vulnerable to harmful genetic and demographic changes caused by habitat fragmentation and population isolation (other maps available online). ${ }^{8}$ Such vulnerability maps can be used to identify isolated and combined genetic and/or demographic factors influencing population persistence, and to evaluate the interactions between environmental change and demogenetic characteristics (e.g., gene flow, dispersal, migration).

\section{Pilot study of climate change effects on bull trout}

As climate warming rapidly progresses, salmonids and other aquatic biota must adapt in place through phenotypic and genetic means, shift to track suitable habitats (i.e., climatic niches), or be extirpated (Crozier et al. 2008, McCullough et al. 2009). We found that stream temperature increases that restrict movements and further reduce suitable habitats to headwater streams are likely to fragment habitat networks, thereby decreasing fish population abundance and genetic

${ }^{8}$ http://ptolemy.dbs.umt.edu/pvm/ diversity, both of which are critical for persistence (Rieman and Allendorf 2001). Bull trout have thermal niches that are several degrees colder than those of other trout and char species (Selong et al. 2001), so natal spawning and rearing habitats are often fragmented and constrained to the coldest headwater streams (Jones et al. 2014), which may provide refugia from predicted stream warming and hydrologic changes associated with climate warming. Although climate change may have played a role in declining populations over the past 30 years in the Flathead system, most declines are due to expansion of nonnative lake trout (Ellis et al. 2011, Muhlfeld et al. 2012).

Not all populations responded to the change in riverscape resistance as expected. Specifically, the response time and magnitude of change in vulnerability metrics was dependent on a population's carrying capacity and abundance at the time of perturbation. For example, both populations 7 and 14 had $\sim 0.50$ probability of returning under current temperature conditions, which was reduced to $\sim 0.20$ in the future. But because population 7's carrying capacity was considerably larger than population 14's $(K=966$ and 74, respectively), both $D_{\mathrm{v}}$ and $G_{\mathrm{v}}$ of population 7 were lower (population 7, $D_{\mathrm{v}}=1.47, G_{\mathrm{v}}=1.62$; population 14, $\left.D_{\mathrm{v}}=1.55, G_{\mathrm{v}}=2.01\right)$. This is not surprising given the importance of effective population size (e.g., Waples et al. 2013), but underscores the need to explore how movement interacts with habitat quality and composition, and the resulting variation in local carrying capacities and census sizes, to affect demographic and genetic connectivity. Nonetheless, our pilot empirical analysis provides a starting point to begin understanding the relative demographic and genetic vulnerability of bull trout populations to increases in stream temperatures. For migratory salmonids that have adapted to use large interconnected river and lake systems, such as bull trout in the Flathead River basin, conserving the connectivity, size, and extent of existing high-quality habitats free of nonnative fishes will be an important conservation strategy, as well as helping to guide restoration opportunities to mitigate the effects of climate change and other cumulative stressors (Muhlfeld and Marotz 2005, D'Angelo and Muhlfeld 2013).

\section{Future research}

Future programming work and simulations with real data are needed to assess sensitivity and uncertainty in real populations, which is a primary goal of most modeling efforts. Simulations could be used to track the behavior of each genetic and demographic metric and identify which metrics are most sensitive for certain species and life histories (e.g., migratory vs. nonmigratory life histories), stream networks, or fragmentation scenarios. Likewise, sensitivity analysis with a range of initial conditions controlling habitat quality and densitydependent processes along with reasonable demogenetic simulation parameters and riverscape surfaces could be 
$G_{v}$

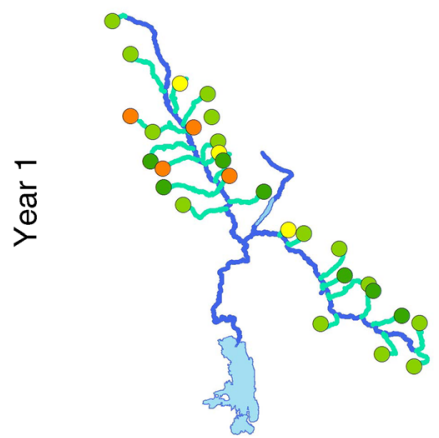

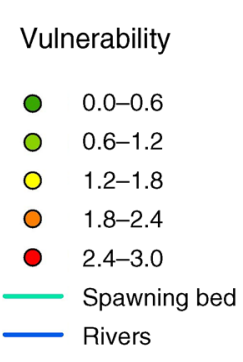

$D_{v}$

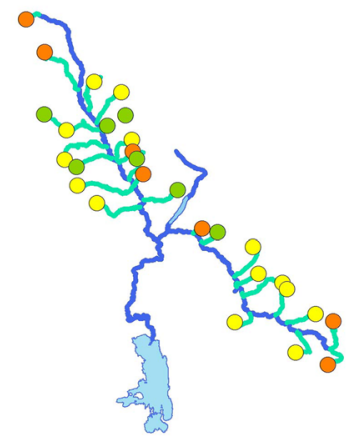

Current

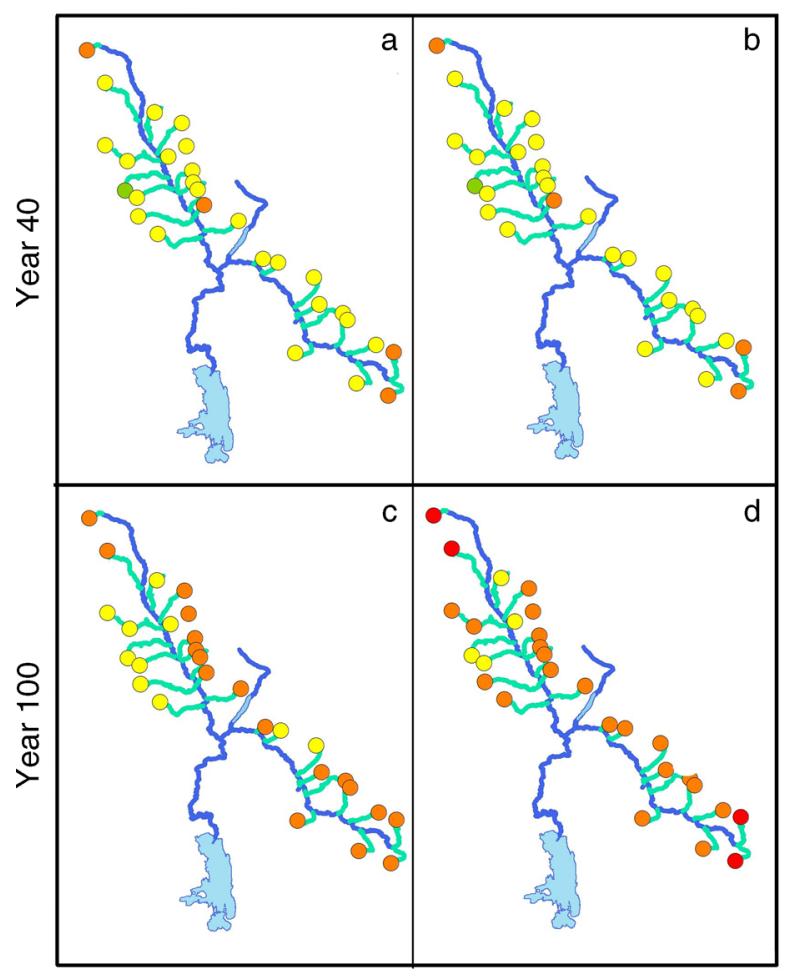

Current

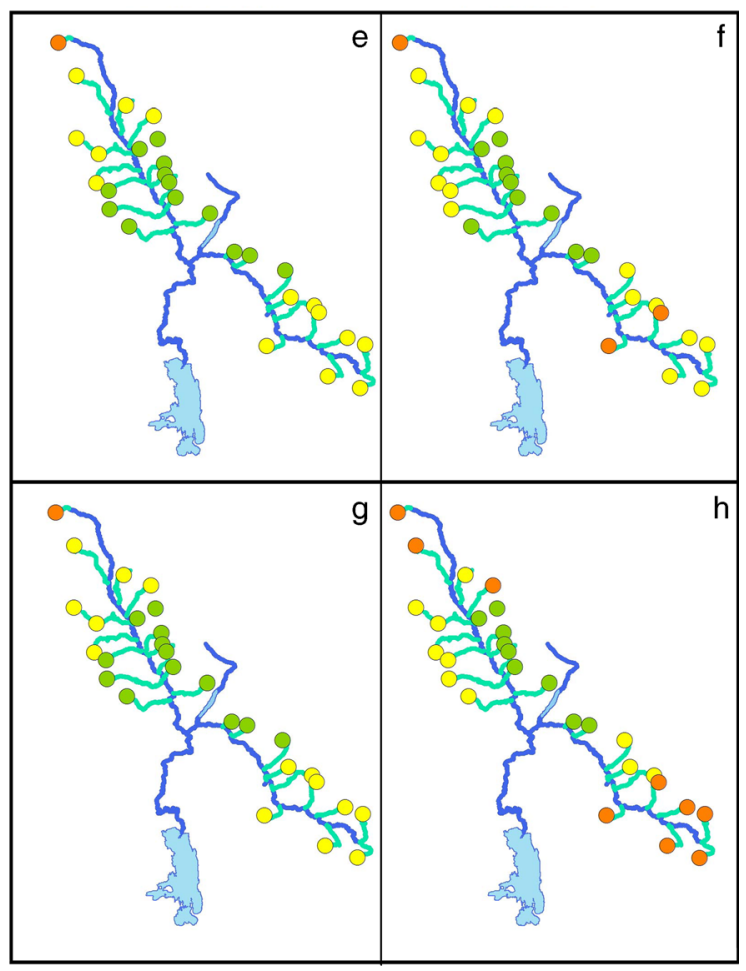

FIG. 9. Vulnerability heat maps for bull trout populations. Vulnerability indices for each of the 28 populations are represented by colors (red is the highest and green is the lowest) for $G_{\mathrm{v}}$ and $D_{\mathrm{v}}$. Current temperature was used for years $0-40$ and an example of vulnerability at year 1 is shown on the top row. At year 40, the modeled future temperature surface was inserted and the two scenarios are compared at this instance on the second row. The final year 100 of the simulations is plotted on the last row.

conducted to understand which genetic and demographic metrics provide earliest detection of population vulnerability. An advantage of resistance surface modeling is that many different surfaces can be simulated and compared to identify the surface (i.e., hypothesis) that best explains the observed demogenetic pattern (e.g., Cushman et al. 2006, Shirk et al. 2010).

Empirical performance evaluations of the vulnerability metrics should be conducted using time-series data with historical demogenetic information and riverscape variables (e.g., temperature; Hitt et al. 2003, Waples et al. 2004, Isaak et al. 2012). For example, environmental data from a previous period could be used in the models to predict current demographic and genetic attributes of focal populations, and those predictions could then be tested with empirical data. However, there could be a mismatch in the responses of demographic and genetic signatures, as well as complex effects of the sampling design (e.g., Oyler-McCance et al. 2012) and temporal lags (e.g., Landguth et al. 2010) in population response to riverscape surfaces. Therefore, determining the sensitivity of model output to variation in the spatial and temporal resolution of empirical inputs (i.e., counts and number of markers) is an area of important 
research. Once systems are appropriately empirically parameterized and thorough sensitivity analysis performed, future simulations could then include environmental scenarios under different rates of climate change (e.g., general circulation models for temperature), thus providing uncertainty analysis for future riverscape resistance surfaces (e.g., Wenger et al. 2013).

Future simulations could also use empirical data from aquatic (e.g., fish) populations to assess the power of different DNA marker sets to detect isolation threats and thus assess vulnerability. For example, observed allelic diversity and differentiation $\left(G_{\mathrm{ST}}\right)$ values could be used to initialize simulations and assess the power and relative sensitivity of a set of markers (e.g., SNPs, AFLPs, or microsatellites) to detect population fragmentation (e.g., selection-driven vs. adaptive markers; Landguth and Balkenhol 2012).

Finally, this approach can provide a foundation for studying adaptive riverscape genetics by including natural selection in network-scale connectivity models. Future simulations could incorporate selection coefficients that vary not only for genotypes, but also in space (and time) as functions of local environmental conditions (Landguth et al. 2012c), which allows the assessment of population vulnerability while considering adaptive capacity and adaptive genetic variation (Glick et al. 2011). Information from emerging genomic techniques such as next-generation sequencing could be used to help parameterize adaptive responses to different selective pressures (e.g., Hohenlohe et al. 2013, Narum et al. 2013).

\section{Conclusions}

We introduce a novel simulation modeling framework that uses riverscape resistance (i.e., connectivity) surfaces along with genetic and demographic information from individual-based simulations to assess the vulnerability of populations to environmental variation and anthropogenic impacts. This framework allows assessment of the contribution of individual genetic and demographic metrics (e.g., gene diversity and dispersal) to population vulnerability, and provides an overall demogenetic vulnerability index (combining all metrics) for each population within a stream network. The framework is flexible enough to include a range of alternative genetic and demographic metrics and to assess the interaction of environmental variables of interest for nearly any species or riverscape scenario. We show that different metrics have different relative sensitivities under four hypothetical (but realistic) resistance barrier scenarios for early detection of population isolation and vulnerability. Using empirical data in a pilot study on bull trout, we illustrate the usefulness of this approach for developing quantitative simulation-based predictions of climate change effects on connectivity and population vulnerability. We hope this vulnerability modeling framework stimulates additional modeling developments and applications to help identify populations vulnerable to environmental change, and to improve conservation and management of freshwater populations, species, and ecosystems.

\section{ACKNOWLEDGMENTS}

We thank K. Keenan for discussions of fixation indices, S. Wenger, and three anonymous reviewers for their comments. We are grateful to the Department of the Interior Northwest Climate Science Center and the Great Northern Landscape Conservation Cooperative for providing funding for this work. E. L. Landguth, C. C. Muhlfeld, L. Jones, and G. Luikart were supported by a grant from the USGS. G. Luikart was partially supported by NSF grants DEB 1067613 and DEB 0742181, G. Luikart and W. Lowe were partially supported by DEB 1258203, and W. Lowe was partially supported by DEB 1050459. L. Jones was partially supported by the NSF under DGE-1313190. Any opinions, findings, and conclusions or recommendations expressed in this material are those of the authors(s) and do not necessarily reflect the views of the NSF. Any use of trade, product, or firm names is for descriptive purposes only and does not imply endorsement by the U.S. Government.

\section{Literature Cited}

Allendorf, F. 1986. Genetic drift and the loss of alleles versus heterozygosity. Zoo Biology 5:181-190.

Allendorf, F. W., P. R. England, G. Luikart, G. A. Ritchie, and N. Ryman. 2008. Genetic effects of harvest on wild animal populations. Trends in Ecology and Evolution 6:327-337.

Allendorf, F. W., P. A. Hohenlohe, and G. Luikart. 2010. Genomics and the future of conservation genetics. Nature Reviews Genetics 11:697-709.

Allendorf, F. W., and G. Luikart. 2007. Conservation and the genetics of populations. Blackwell, Malden, Massachusetts, USA.

Allendorf, F. W., and N. Ryman. 2002. The role of genetics in population viability analysis. Pages $50-85$ in $\mathrm{S}$. R. Beissinger and D. R. McCullough, editors. Population viability analysis. University of Chicago Press, Chicago, Illinois, USA.

Balkenhol, N., F. Gugerli, S. A. Cushman, L. P. Waits, A. Coulon, J. W. Arntzen, R. Holderegger, and H. H. Wagner. 2009. Identifying future research needs in landscape genetics: where to from here? Landscape Ecology 24:455-463.

Balkenhol, N., and E. L. Landguth. 2011. Simulation modeling in landscape genetics: on the need to go further. Molecular Ecology 20:667-670.

Balloux, F. 2001. EASYPOP (version 1.7): a computer program for population genetic simulations. Journal of Heredity 92:301-302.

Brown, J. H., and A. Kodric-Brown. 1977. Turnover rates in insular biogeography: effect of immigration on extinction. Ecology 58:445-449.

Cross, M. S., et al. 2012. The adaptation for conservation targets (ACT) framework: a tool for incorporating climate change into natural resource management. Environmental Management 50:341-351.

Crozier, L. G., A. P. Hendry, P. W. Lawson, T. P. Quinn, M. J. Mantua, J. Battin, R. G. Shaw, and R. B. Huey. 2008. Potential responses to climate change in organisms with complex life histories: evolution and plasticity in Pacific salmon. Evolutionary Applications 1:252-270.

Cushman, S. A., K. S. McKelvey, J. Hayden, and M. K. Schwartz. 2006. Gene flow in complex landscapes: testing multiple hypotheses with causal modeling. American Naturalist 168:486-499.

D'Angelo, V. S., and C. C. Muhlfeld. 2013. Factors influencing the distribution of native bull trout and westslope cutthroat trout in streams of western Glacier National Park, Montana. Northwest Science 87:1-11. 
Downs, C. C., D. Horan, E. Morgan-Harris, and R. Jakubowski. 2006. Spawning demographics and juvenile dispersal of bull trout in Trestle Creek, Idaho. North American Journal of Fisheries Management 26:190-200.

Dunning, J. B., B. J. Danielson, and H. R. Pulliam. 1992. Ecological processes that affect populations in complex landscapes. Oikos 65:169-175.

Ellis, B. K., J. A. Stanford, D. Goodman, C. P. Stafford, D. L. Gustafson, D. A. Beauchamp, D. W. Chess, J. A. Craft, M. A. Deleray, and B. S. Hansen. 2011. Long-term effects of a trophic cascade in a large lake ecosystem. Proceedings of the National Academy of Sciences USA 108:1070-1075.

England, P. R., G. Luikart, and R. S. Waples. 2010. Early detection of population fragmentation using linkage disequilibrium estimation of effective population size. Conservation Genetics 11:2425-2430.

Epperson, B. K., et al. 2010. Utility of computer simulations in landscape genetics. Molecular Ecology 19:3549-3564.

Fagan, W. F. 2002. Connectivity, fragmentation, and extinction risk in dendritic metapopulations. Ecology 83:3243-3249.

Fausch, K. D., B. E. Rieman, J. B. Dunham, M. K. Young, and D. P. Peterson. 2009. Invasion versus isolation: trade-offs in managing native salmonids with barriers to upstream movement. Conservation Biology 23:859-870.

Fausch, K. D., C. E. Torgersen, C. V. Baxter, and H. W. Li. 2002. Landscapes to riverscapes: bridging the gap between research and conservation of stream fishes. Bioscience 52:483-498.

Fraley, J. J., and B. B. Shepard. 1989. Life history, ecology, and population status of migratory bull trout (Salvelinus confluentus) in the Flathead Lake and River system, Montana. Northwest Science 63:133-143.

Frank, B. M., J. J. Piccolo, and P. V. Baret. 2011. A review of ecological models for brown trout: towards a new demogenetic model. Ecology of Freshwater Fish 20:167-198.

Garant, D., S. E. Forde, and A. P. Hendry. 2007. The multifarious effects of dispersal and gene flow on contemporary adaptation. Functional Ecology 21:434-443.

Glick, P., B. A. Stein, and N. A. Edelson. 2011. Scanning the conservation horizon: a guide to climate change vulnerability assessment. National Wildlife Federation, Washington, D.C., USA.

Grant, E. H. C., W. H. Lowe, and W. F. Fagan. 2007. Living in the branches: population dynamics and ecological processes in dendritic networks. Ecology Letters 10:165-175.

Hanski, I., and M. Gilpin. 1991. Metapopulation dynamics: brief history and conceptual domain. Biological Journal of the Linnaean Society 42:3-16.

Hedrick, P. W. 2005. A standardized genetic differentiation measure. Evolution 59:1633-1638.

Hitt, N. P., C. A. Frissell, C. C. Muhlfeld, and F. W. Allendorf. 2003. Spread of hybridization between native westslope cutthroat trout, Oncorhynchus clarki lewisi, and nonnative rainbow trout, Oncorhynchus mykiss. Canadian Journal of Fisheries and Aquatic Sciences 60:1440-1451.

Hitt, N. P., and J. H. Roberts. 2012. Hierarchical spatial structure of stream fish colonization and extinction. Oikos 121:127-137.

Hohenlohe, P. A., M. D. Day, S. J. Amish, M. R. Miller, N. Kamps-Hughes, M. C. Boyer, C. C. Muhlfeld, F. W. Allendorf, E. A. Johnson, and G. Luikart. 2013. Genomic patterns of introgression in rainbow and westslope cutthroat trout illuminated by overlapping paired-end RAD sequencing. Molecular Ecology 22:3002-3013.

Isaak, D. J., C. C. Muhlfeld, A. S. Todd, R. Al-Chokhachy, J. Roberts, J. L. Kershner, K. D. Fausch, and S. W. Hostetler. 2012. The past as prelude to the future for understanding 21st-century climate effects on Rocky Mountain trout. Fisheries 37:542-556.

IUCN (International Union for Conservation of Nature) Standards and Petitions Subcommittee. 2010. Guidelines for using the IUCN Red List categories and criteria. IUCN, Gland, Switzerland.

Jarić, I., T. Ebenhard, and M. Lenhardt. 2010. Population viability analysis of the Danube sturgeon populations in a VORTEX simulation model. Reviews in Fish Biology and Fisheries 20:219-237.

Jones, L. A., C. C. Muhlfeld, L. A. Marshall, B. McGlynn, and J. Kershner. 2014. Estimating thermal regimes of bull trout and assessing the potential effects of climate warming on critical habitats. River Research and Applications 30(2):204216.

Jost, L. 2008. $G_{\mathrm{ST}}$ and its relatives do not measure differentiation. Molecular Ecology 17:4015-4026.

Keenan, K., P. McGinnity, T. F. Cross, W. C. Crozier, and P. A. Prodöhl. 2013. diveRsity: an R package for the estimation and exploration of population genetics parameters and their associated errors. Methods in Ecology and Evolution 4(8): 782-788.

Lande, R. 1994. Risk of population extinction from new deleterious mutations. Evolution 48:1303-1312.

Landguth, E. L., and N. Balkenhol. 2012. Relative sensitivity of neutral versus adaptive genetic data for assessing population differentiation. Conservation Genetics 13:1421-1426.

Landguth, E. L., and S. A. Cushman. 2010. CDPOP: A spatially explicit cost distance population genetics program. Molecular Ecology Resources 10:156-161.

Landguth, E. L., S. A. Cushman, and N. A. Johnson. $2012 c$. Simulating natural selection in landscape genetics. Molecular Ecology Resources 12:363-368.

Landguth, E. L., S. A. Cushman, M. K. Schwartz, M. Murphy, K. S. McKelvey, and G. Luikart. 2010. Quantifying the lag time to detect barriers in landscape genetics. Molecular Ecology 19:4179-4191.

Landguth, E. L., B. K. Hand, J. M. Glassy, S. A. Cushman, and M. Sawaya. 2012b. UNICOR: a species corridor and connectivity network simulator. Ecography 12:9-14.

Landguth, E. L., C. C. Muhlfeld, and G. Luikart. $2012 a$. CDFISH: an individual-based, spatially-explicit, landscape genetics simulator for aquatic species in complex riverscapes. Conservation Genetics Resources 4:133-136.

Leberg, P. L. 1992. Effects of a population bottleneck on genetic variation as measured by allozyme electrophoresis. Evolution 46:477-494.

Levins, R. 1969. Some demographic and genetic consequences of environmental heterogeneity for biological control. Bulletin of the Entomological Society of America 15:237240.

Lowe, W. H., and F. W. Allendorf. 2010. What can genetics tell us about population connectivity? Molecular Ecology 19:3038-3051.

Luikart, G., J. M. Cornuet, and F. W. Allendorf. 1999. Temporal changes in allele frequencies provide estimates of population bottleneck size. Conservation Biology 13:523530.

Luque, S., S. Saura, and M. J. Fortin. 2012. Landscape connectivity analysis for conservation: insights from combining new methods with ecological and genetic data. Landscape Ecology 27:153-157.

McCullough, D. A., et al. 2009. Research in thermal biology: burning questions for coldwater stream fishes. Reviews in Fisheries Science 17:90-115.

Mills, L. S. 2007. Conservation of wildlife populations: demography, genetics, and management. Blackwell, Malden, Massachusetts, USA.

Mote, P. W., and E. P. Salathe. 2009. Future climate in the Pacific Northwest. Pages 21-43 in J. S. Littell, M. McGuireElsner, M. C. Whitley-Binder, and A. K. Snover, editors. The Washington climate change impacts assessment: evaluating Washington's future in a changing climate. Climate Impacts Group, University of Washington, Seattle, Washington, USA. 
Muhlfeld, C. C., J. J. Giersch, and B. Marotz. 2012. Seasonal movements of non-native lake trout in a connected lake and river system. Fisheries Management and Ecology 19:224232.

Muhlfeld, C. C., and B. Marotz. 2005. Seasonal movement and habitat use by subadult bull trout in the upper Flathead River system, Montana. North American Journal of Fisheries Management 25:797-810.

Muhlfeld, C. C., M. L. Taper, D. F. Staples, and B. B. Shepard. 2006. Observer error structure in bull trout redd counts in Montana streams: implications for inference on true redd numbers. Transactions of the American Fisheries Society 135:643-654.

Narum, S. R., N. R. Campbell, K. A. Meyer, M. R. Miller, and R. W. Hardy. 2013. Thermal adaptation and acclimation of ectotherms from differing aquatic climates. Molecular Ecology 22:3090-3097.

Nei, M. 1973. Analysis of gene diversity in subdivided populations. Proceedings of the National Academy of Sciences USA 70:3321-3323.

Nei, M., and R. K. Chesser. 1983. Estimation of fixation indices and gene diversities. Annals of Human Genetics 47:253-259.

Northcote, T. G. 1997. Potamodromy in salmonidae-living and moving in the fast lane. North American Journal of Fisheries Management 17:1029-1045.

Oyler-McCance, S. J., B. C. Fedy, and E. L. Landguth. 2013. Sample design effects in landscape genetics. Conservation Genetics 14:275-285.

Parmesan, C. 2006. Ecological and evolutionary responses to recent climate change. Annual Review of Ecological Systems 37:637-669.

Parmesan, C., and G. Yohe. 2003. A globally coherent fingerprint of climate change impacts across natural systems. Nature 421:37-42.

Pertoldi, C., and C. Topping. 2004. The use of agent-based modelling of genetics in conservation genetics studies. Journal for Nature Conservation 12:111-120.

Python Software Foundation. 2013. Python Language Reference, version 2.7.6. http://www.python.org

R Development Core Team. 2012. R: A language and environment for statistical computing. R Foundation for Statistical Computing, Vienna, Austria. http://www. r-project.org

Rieman, B. E., and F. W. Allendorf. 2001. Effective population size and genetic conservation criteria for bull trout. North American Journal of Fisheries Management 21:756-764.

Rieman, B. E., and D. L. Myers. 1997. Use of redd counts to detect trends in bull trout (Salvelinus confluentus) populations. Conservation Biology 11:1015-1018.

Root, T. L., J. T. Price, K. R. Hall, S. H. Schneider, C. Rosenzweig, and J. A. Pounds. 2003. Fingerprints of global warming on wild animals and plants. Nature 421:57-60.

Ryman, N., F. Utter, and L. Laikre. 1995. Protection of intraspecific biodiversity of exploited fishes. Reviews in Fish Biology and Fisheries 5:417-446.

Schindler, D. E., R. Hilborn, B. Chasco, C. P. Boatright, T. P. Quinn, L. A. Rogers, and M. S. Webster. 2010. Population diversity and the portfolio effect in an exploited species. Nature 465:609-612.

Schlosser, I. J., and P. L. Angermeier. 1995. Spatial variation in demographic processes of lotic fishes: conceptual models, empirical evidence, and implications for conservation. American Fisheries Society Symposium 17:392-401.

Selong, J. H., T. E. McMahon, A. V. Alexander, and F. T. Barrows. 2001. Effect of temperature on growth and survival of bull trout, with application of an improved method of determining thermal tolerance in fishes. Transactions of the American Fisheries Society 130:1026-1037.

Shirk, A., D. O. Wallin, S. A. Cushman, R. C. Rice, and C. Warheit. 2010. Inferring landscape effects on gene flow: a new multi-scale model selection framework. Molecular Ecology 19:3603-1619.

Spear, S., N. Balkenhol, M.-J. Fortin, B. McRae, and K. Scribner. 2010. Use of resistance surfaces for landscape genetic studies: considerations for parameterization and analysis. Molecular Ecology 19:3576-3591.

Spencer, C. C., J. E. Neigel, and P. L. Leberg. 2000. Experimental evaluation of the usefulness of microsatellite DNA for detecting demographic bottlenecks. Molecular Ecology 9:1517-1528.

Vannote, R. L., G. W. Minshall, K. W. Cummins, J. R. Sedell, and S. E. Cushing. 1980. The river continuum concept. Canadian Journal of Fisheries and Aquatic Sciences 37:130 137.

Walther, G. R., E. Post, P. Convey, A. Menzel, C. Parmesan, T. J. C. Beebee, J. M. Fromentin, O. Hoegh-Guldberg, and F. Bairlein. 2002. Ecological responses to recent climate change. Nature 416:389-395.

Waples, R. S., and C. Do. 2010. Linkage disequilibrium estimates of contemporary $N_{\mathrm{e}}$ using highly variable genetic markers: a largely untapped resource for applied conservation and evolution. Evolutionary Applications 3:244-262.

Waples, R. S., G. Luikart, J. R. Faulkner, and D. A. Tallmon. 2013. Simple life-history traits explain key effective population size ratios across diverse taxa. Proceedings of the Royal Society B 280:20131339.

Waples, R. S., D. J. Teel, J. Myers, and A. Marshall. 2004. Life history divergence in Chinook salmon: historic contingency and parallel evolution. Evolution 58:386-403.

Weaver, T. 2006. Bull trout status report of the upper Flathead River drainage. Montana Fish, Wildlife and Parks, Kalispell, Montana, USA.

Wenger, S. J., et al. 2011. Flow regime, temperature, and biotic interactions drive differential declines of trout species under climate change. Proceedings of the National Academy of Sciences USA 108:14175-14180.

Wenger, S. J., C. H. Luce, A. F. Hamlet, D. J. Isaak, and H. M. Neville. 2010. Macroscale hydrologic modeling of ecologically relevant flow metrics. Water Resources Research 46:10.

Wenger, S. J., N. A. Som, D. C. Dauwalter, D. J. Isaak, H. M. Neville, C. H. Luce, J. B. Dunham, M. K. Young, K. D. Fausch, and B. E. Rieman. 2013. Probabilistic accounting of uncertainty in forecasts of species distributions under climate change. Global Change Biology 19(11):3343-3354.

Whited, Diane C., J. S. Kimball, J. A. Lucotch, N. K. Maumenee, H. Wu, S. D. Chilcote, and J. A. Stanford. 2012. A riverscape analysis tool developed to assist wild salmon conservation across the North Pacific Rim. Fisheries 37:305-314.

Wilson, G. A., and B. Rannala. 2003. Bayesian inference of recent migration rates using multilocus genotypes. Genetics 163:1177-1191.

\section{Supplemental Material}

\section{Appendix}

Demogenetic vulnerability metrics and indices for the hypothetical modeling scenarios (Ecological Archives A024-088-A1). 